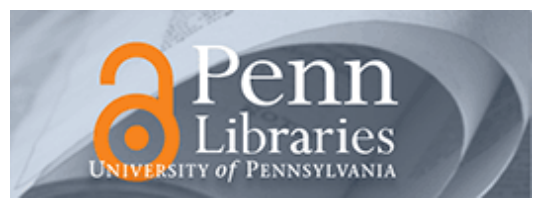

University of Pennsylvania

ScholarlyCommons

Operations, Information and Decisions Papers

Wharton Faculty Research

$5-2012$

\title{
Designing Ranking Systems for Hotels on Travel Search Engines by Mining User-Generated and Crowdsourced Content
}

Anindya Ghose

University of Pennsylvania

Panagiotis G. Ipeirotis

Beibei Li

Follow this and additional works at: https://repository.upenn.edu/oid_papers

Part of the Marketing Commons, Other Business Commons, Recreation Business Commons, Sales and Merchandising Commons, and the Tourism and Travel Commons

\section{Recommended Citation}

Ghose, A., Ipeirotis, P. G., \& Li, B. (2012). Designing Ranking Systems for Hotels on Travel Search Engines by Mining User-Generated and Crowdsourced Content. Marketing Science, 31 (3), 493-520.

http://dx.doi.org/10.1287/mksc.1110.0700

This paper is posted at ScholarlyCommons. https://repository.upenn.edu/oid_papers/100

For more information, please contact repository@pobox.upenn.edu. 


\title{
Designing Ranking Systems for Hotels on Travel Search Engines by Mining User- Generated and Crowdsourced Content
}

\begin{abstract}
User-generated content on social media platforms and product search engines is changing the way consumers shop for goods online. However, current product search engines fail to effectively leverage information created across diverse social media platforms. Moreover, current ranking algorithms in these product search engines tend to induce consumers to focus on one single product characteristic dimension (e.g., price, star rating). This approach largely ignores consumers' multidimensional preferences for products. In this paper, we propose to generate a ranking system that recommends products that provide, on average, the best value for the consumer's money. The key idea is that products that provide a higher surplus should be ranked higher on the screen in response to consumer queries. We use a unique data set of U.S. hotel reservations made over a three-month period through Travelocity, which we supplement with data from various social media sources using techniques from text mining, image classification, social geotagging, human annotations, and geomapping. We propose a random coefficient hybrid structural model, taking into consideration the two sources of consumer heterogeneity the different travel occasions and different hotel characteristics introduce. Based on the estimates from the model, we infer the economic impact of various location and service characteristics of hotels. We then propose a new hotel ranking system based on the average utility gain a consumer receives from staying in a particular hotel. By doing so, we can provide customers with the "best-value" hotels early on. Our user studies, using ranking comparisons from several thousand users, validate the superiority of our ranking system relative to existing systems on several travel search engines. On a broader note, this paper illustrates how social media can be mined and incorporated into a demand estimation model in order to generate a new ranking system in product search engines. We thus highlight the tight linkages between user behavior on social media and search engines. Our interdisciplinary approach provides several insights for using machine learning techniques in economics and marketing research.
\end{abstract}

\section{Keywords}

user-generated content, social media, search engines, hotels, ranking system, structural models, text mining, crowdsourcing

\section{Disciplines}

Marketing | Other Business | Recreation Business | Sales and Merchandising | Tourism and Travel 


\title{
Designing Ranking Systems for Hotels on Travel Search Engines by Mining User-Generated and Crowd-Sourced Content ${ }^{1}$
}

\author{
Anindya Ghose \\ Stern School of Business, New York University, aghose@stern.nyu.edu \\ Panagiotis G. Ipeirotis \\ Stern School of Business, New York University, panos@stern.nyu.edu \\ Beibei Li \\ Stern School of Business, New York University, bli@stern.nyu.edu
}

\begin{abstract}
User-Generated Content (UGC) is changing the way consumers shop for goods. Based on a unique dataset of hotel reservations over a 3-month period from Travelocity.com, we estimate the demand for hotels using a hybrid random coefficient structural model that data from a variety of information sources. We obtain user-generated data from three sources: (i) text of hotel reviews from two well-known travel search engines, Travelocity.com and Tripadvisor.com, (ii) social geo-tags from Geonames.org identifying the different location-based attributes of hotels, and (iii) user-contributed opinions on the most important hotel characteristics by accessing a wide consumer demographic using Amazon Mechanical Turk. These data sources are merged with satellite images of the different hotel locations to create one comprehensive dataset summarizing the location and service characteristics of the hotels in our sample. We use text analysis techniques to measure the quality of available reviews. Using these analyses, we quantify how the extent of subjectivity, readability, complexity and other stylistic features of user-generated reviews are associated with hotel room sales. Finally, based on the hybrid model we estimate the weight that consumers place on different location and service-related features of hotels.

We extend the basic model to examine interaction effects between travel purpose, price, and hotel characteristics. Business travelers are the least price sensitive while tourists are the most price sensitive. Business travelers have the highest marginal valuation for hotels located closer to a highway and having easy access to public transportation. In contrast, romance travelers have the highest marginal valuation for hotels located closer to a beach and those with a high service rating.

As the ultimate goal of this research, we use the generated estimates from our model in order to build a better ranking system for hotel search. Specifically, we leverage the econometric analysis and compute the average utility gain that a consumer gets by staying in a particular hotel. We propose to rank the hotels, in response to a search query, using this utility gain, which is a measure of "value" that a consumer gets from this transaction. By doing so, one can provide customers with the "best-value" hotels early on, thereby improving the quality of online hotel search compared to existing systems. Several field experiments in six major cities (New York, Los Angeles, San Francisco, Orlando, New Orleans, and Salt Lake City), using 15,600 ranking comparisons from Amazon Mechanical Turk, suggest that our ranking system is superior to existing systems.
\end{abstract}

\footnotetext{
${ }^{1}$ We thank Susan Athey, Peter Fader, Francois Moreau, Aviv Nevo, Minjae Song, Daniel Spulber, and Hal Varian for extremely helpful comments that have significantly improved the paper. We also thank participants at NBER IT Economics \& Productivity Workshop, 2010 Workshop on Digital Business Models, 2010 Marketing Science Conference, Searle Research Symposium on the Economics and Law of Internet Search at NorthWestern University, Customer Insights Conference at Yale University, 2010 SCECR conference, 2009 Workshop on Information Technology and Systems (WITS), 2009 Workshop on Economics and Information Systems and seminar participants at Temple University, University of Minnesota for helpful comments. Anindya Ghose and Panos Ipeirotis acknowledge the financial support from National Science Foundation CAREER Awards IIS-0643847 and IIS0643846, respectively. Support was also provided through a MSI-Wharton Interactive Media Grant (WIMI) and a Microsoft Virtual Earth Award. The authors thank Travelocity for providing the data and Uthaman Palaniappan for research assistance.
} 


\section{Introduction}

Consumers today use a variety of information sources in order to learn more about their potential purchases. It is now widely acknowledged that local search for hotel accommodations are a component of general Web searches that are increasing in popularity as more and more users search for prices and reserve their trips online. In travel search, a variety of resources are available that provide information to potential travelers about the hotels in their destination. Customers try to identify hotels that satisfy particular criteria, such as service amenities, location attributes, and so on. Once they identify the candidate hotels, customers would typically look at the price and determine if the "real value" of that hotel matches the corresponding price. Hence, locating a hotel with the specific desired characteristics, but without compromising on the value, becomes an important question.

Most online travel search engines only provide rudimentary ranking facilities, typically using a single ranking criterion, such as distance from the city center, star ratings, and price per night. This approach has quite a few shortcomings. First, it ignores the multidimensional preferences of consumers, in that a customer's ideal choice may consist of several hotel-specific attributes. Second, it does not take into account the heterogeneous preferences of consumers towards hotel characteristics. Given a user query, the ranking mechanisms tend to assume that people's preferences towards the set of hotel characteristics are homogeneous. This leads them to provide an identical ranking recommendation for all customers, regardless of their age, income or purchase context. Third, it largely ignores characteristics related to the location of the hotel, for instance, in terms of proximity to the beach, or proximity to a downtown shopping area. These location-based features represent important characteristics that can influence the desirability of a particular hotel.

In this paper, we propose to build a system that ranks each hotel according to the expected utility gain across the consumer population. The advantage of this system is that it uses consumer utility theory to design a scalar utility score with which to rank hotels while incorporating all of the observed dimensions of hotel quality. Currently, there are no established measures that quantify the economic impact of various internal (service) and external (location) characteristics on hotel demand. However, search engines do have access to a lot of user-generated information not only on their own site but across other social media sites as well. Such social media data can be useful for estimating the weights that consumers place on different hotel characteristics.

We use a unique dataset of hotel reservations from Travelocity.com. The dataset contains complete information on transactions conducted over a 3-month period from 11/2008 to 1/2009 for 1497 hotels in the United States (US). We have data on user-generated content from three sources: (i) user-generated hotel reviews from two well-known travel search engines, Travelocity.com and Tripadvisor.com, (ii) social-geo tags generated by users identifying different geographic attributes of hotels from Geonames.org, and (iii) user-contributed opinions on the most important hotel characteristics using on-demand surveys and social 
annotations from users on Amazon Mechanical Turk (AMT). ${ }^{2}$ Moreover, since some location-based characteristics, such as proximity to the beach, are not directly measurable based on UGC, we use image classification techniques to infer such features from the satellite images of the area. These different data sources are then merged to create one comprehensive dataset summarizing the location and service characteristics of all the hotels. Our empirical modeling and analyses enables us to compute the "average utility gain" from a particular hotel based on the estimation of price elasticities and average utilities. Thereafter, we aim to generate hotel rankings that are superior to existing ranking techniques seen in travel search engines.

Our work involves four steps:

i. Identify the important hotel location and service characteristics that influence hotel demand and collect that data.

ii. Estimate how these hotel characteristics influence demand and quantify their marginal effects using a structural model.

iii. Impute the expected utility from each hotel based on demand estimation and generate rankings based on them

iv. Validate our ranking system by conducting field experiments using AMT.

More specifically, in the first step, we determine the particular hotel characteristics that are most valued by customers, and thus, influence the aggregate demand of the hotels. Beyond the directly observable characteristics, such as the "number of stars," provided by most third-party travel websites, many users also tend to value location characteristics, such as proximity to the beach, or proximity to downtown shopping areas. In our work, we incorporate satellite image classification techniques and use both human and computer intelligence (in the form of social geo-tagging and text mining of reviews) to infer these location features. In the second step, we use demand estimation techniques (BLP 1995, Berry and Pakes 2007, Song 2010) and estimate the economic value associated with various location and service characteristics. This enables us to quantitatively analyze how each feature influences demand and estimate its importance relative to the other features. In the third step, after inferring to the economic significance of the location and service-based hotel characteristics, we incorporate them into designing a hotel ranking system based on the expected utility gain from a given hotel. By doing so, we can provide customers with the "best-value" hotels early on, thereby improving the quality of online hotel search compared to existing systems. In the final step, we validate our proposed ranking system by conducting field experiments with

\footnotetext{
2“Social annotation" is an annotation associated with a web resource (e.g., a web page, an online image, etc.). On a social annotation system (e.g., the Amazon Mechanical Turk tool in our case), a user can add, modify or remove information from the web resource without modifying the resource itself. The annotations can be thought of as a layer on top of the existing resource, and this annotation layer is usually visible to other users who share the same annotation system. In such cases, the web annotation tool is a type of social software tool.
} 
users on the popular on-demand social annotation site, AMT across six different cities. Our key results are as follows.

i. Five location-based characteristics have a positive impact on hotel demand: "number of external amenities," "presence near a beach", "presence near public transportation," "presence near a highway," and "presence near a Downtown." Two location-based characteristics have a negative impact on hotel demand: "Annual crime rate," and "presence near a lake/river." The textual content and style of reviews also demonstrate a statistically significant association with demand. Reviews that are less complex, have words with fewer syllables, and with fewer spelling errors have a positive influence on demand. Reviews with higher number of characters and written using simple language are also positively associated with demand. These results suggest that consumers can form an image about the quality of a hotel by judging the quality of the user-generated reviews. Consumers prefer hotels with reviews that contain objective information (such as factual descriptions of hotels) relative to subjective information, indicating that they do not trust completely hotel-provided descriptions and prefer confirmation from third-parties. Consumers also prefer to stay in hotels with reviews written in a "consistent objective style" rather than staying in a hotel where the user reviews discuss more subjective aspects of the accommodation.

ii. We extend the basic model to examine interaction effects between travel purpose, price, and hotel characteristics. Our results show that consumer preferences for location and service characteristics are influenced by price and travel purpose. For instance, business travelers are the least price sensitive while tourists are the most price sensitive. In addition, business travelers have the highest marginal valuation for hotels located closer to a highway and having easy access to public transportation. In contrast, romance travelers have the highest marginal valuation for hotels located closer to a beach and those with a high service rating.

iii. A comparison of the model that conditions on the UGC variables with a model that does not shows that the model with UGC variables outperformed the latter in both in- and out-of-sample analyses. We conduct additional model fit comparisons and find that the model's predictive power drops the most when excluding all the location variables, followed by the service variables and then the UGC variables.

iv. We also conduct several counterfactual experiments which shed light on how price cuts affects demand in different location environments and how they affect substitution patterns across competing hotels. Upon comparing locations with Beach and highway (which represents the typical west/south coast setting), and locations with Downtown, transportation and external amenities (which represents the typical big city setting), we find that a price cut leads to a lower increase in demand in a big city setting than that in coastline setting. That is, consumers tend to react much less sensitively to hotel price changes in a typical "big city." In addition, we find that the closest substitutes for 4-star hotels are 5- 
star hotels; the closest substitutes for 3-star hotels are 4-star and 2-star hotels; the closest substitutes for 2-star hotels are 1-star hotels.

Our key contributions can be summarized as follows. First, we demonstrate the value of using multiple and diverse user-generated data sources towards examining the economic value of different location and service characteristics of hotels using a structural model of demand estimation. Customers today make their decisions in an environment with the plethora of available data. It is possible that some consumers check the characteristics of the hotel using tourist guides and mapping applications, or consult online review sites to determine the quality of the hotel and its amenities. In order to replicate this decisionmaking environment, we construct an exhaustive dataset, collecting as much information as possible about the hotels in our data, using a variety of data sources, and a variety of methodologies such as text mining, on-demand annotations, and image classification. We demonstrate the significance of different sources of data by conduct model fit comparisons between models that condition for one set of variables vs. others.

Second, our empirical estimates enable us to propose a new ranking system for hotel search based on the computation of expected utility gain from each hotel. The proposed new ranking system for hotels ranks the hotels based on the computation of expected utility gain, which measures the "value" that a consumer gets from the transaction. The key notion is that in response to a consumer search query, the system would recommend and rank those hotels higher that provide a higher "value for money" by taking into account consumers' multi-dimensional preferences.

Finally, to evaluate the quality of our ranking technique, we conducted a user study toward which we designed and executed several field experiments on AMT across six different markets in the US. Using more than 15,000 user responses for comparing different rankings, we show that our proposed ranking performs significantly better than several baseline-ranking systems that are being currently used by travel search engines. A post-experimental survey revealed users strongly preferred the diversity of the retrieved results, given that our list consisted of a mix of hotels cutting across several price and quality ranges. This indicates that customers prefer a list of hotels that each specializes in a variety of characteristics, rather than a variety of hotels that each specializes in only one characteristic. Besides providing consumers with direct economic gains, such a ranking system can lead to non-trivial reduction in consumer search costs. Furthermore, by directing the customers to hotels that are better matches for their interests, this can lead to increased usage of travel search engines.

The rest of the paper is organized as follows. Section 2 discusses related work and places our work in the context of prior literature. Section 3 discusses the work related to the data preparation, including the methods used to identify important hotel characteristics, the steps undertaken to conduct the surveys on AMT to elicit user opinions, and the text mining techniques used to parse user-generated reviews. In Sections 4 and 5, we provide an overview of our econometric approach, and discuss empirical results, 
respectively. In Section 6, we discuss how one can apply our approach to design a real-world application, such as a ranking system for hotel search. In Section 7, we conclude.

\section{Prior Literature}

Our paper draws from multiple streams of work. A key challenge is to bridge the gap between the textual and qualitative nature of review content and the quantitative nature of discrete choice models. With the rapid growth and popularity of the user-generated content on the Web, a new area of research applying text mining technique to product reviews has emerged. The first stream of this research has focused on the sentiment analysis of product reviews (Hu \& Liu 2004, Pang \& Lee 2004, Das \& Chen 2007). This stimulated additional research on identifying product features in which consumers expressed their opinions (Hu \& Liu 2004, Scaffidi et al. 2007, Snyder \& Barzilay 2007). The automated extraction of product attributes has also received attention in the recent marketing literature (Lee \& Bradlow 2007).

The hypothesis that product reviews affect product sales has received strong support in prior empirical studies (for example, Godes and Mayzlin 2004, Chevalier and Mayzlin 2006, Liu 2006, Dellarocas et al. 2007, Duan et al. 2008, Forman et al. 2008, Moe 2009). However, these studies focus only on numeric review ratings (e.g., the valence and volume of reviews) in their empirical analysis. Only a handful of empirical studies have formally tested whether the textual information embedded in online user-generated content can have an economic impact (Ghose et al. 2006, Eliashberg et al. 2007, Archak et al. 2008, Ghose and Ipeirotis 2010). However, these studies do not focus on estimating the impact of user-generated reviews in influencing sales beyond the effect of numeric review ratings. In addition, researchers using only numeric ratings have to deal with issues like self-selection bias ( $\mathrm{Li}$ and Hitt 2008) and bimodal distribution of reviews (Hu et al. 2008). More importantly, the matching of consumers to hotels in numerical rating systems is not random. A consumer only rates the hotel that she frequents (i.e. the one that maximizes her utility). Consequently, the average star rating for each hotel need not reflect the population average utility. Due to the above drawbacks, the average numerical star rating assigned to a product may not convey a lot of information to a prospective buyer. Therefore, a key objective of this paper is to analyze the extent to which textual content and linguistic style of user-generated reviews can help us understand consumer choice of hotels.

Our work is related to models of demand estimation. One model that has made a significant contribution to the field is the random coefficient logit model, or BLP 1995 (Berry et al. 1995). Due to the limitations of the product-level "taste shock" in logit models, a new model based on pure product characteristics has been proposed recently (Berry and Pakes 2007). The pure characteristic model (hereafter, PCM) differs from the BLP model in the sense that it does not contain the product-level "taste shock." It describes the consumer heterogeneity, purely based on their different tastes towards individual product characteristics, without considerations on the tastes of certain products as a whole (i.e., brand preference). However in reality, the product-level idiosyncratic "tastes" of different consumers do exist in 
many markets. As pointed out in Song (2010)Song (2010), whether or not one should introduce the product-level "taste shock" should depend on the context of the market. Keeping in mind the two levels of consumer heterogeneity introduced by (1) different travel categories (i.e., family trip, romance, or business trip) and (2) different hotel characteristics, we propose a random coefficient hybrid structural model to identify the latent weight distribution that consumers assign to each hotel characteristic. The outcome of our analysis enables us to compute the expected utility gain from each hotel and rank them accordingly on a travel search engine.

Finally, our paper is related to the work in online recommender systems. By generating a novel ranking approach for hotels, we aim to improve the recommendation strategy for travel search engines and provide customers with the "best-value" hotels early on in the search process. In the marketing literature, several model-based recommendation systems have been proposed to predict preferences for recommended items (Ansari et al. 2000, Ying et al. 2005, Bodapati 2008). A more recent trend along this line is Adaptive Personalization Systems (Ansari and Mela 2003, Rust and Chung 2006, Chung et al. 2009).

\section{Data Description}

Our dataset consisted of observations from 1479 hotels in the US. We collected data from various sources to conduct our study. We had 3 months of hotel transaction data from Travelocity.com from November 12008 to January 31 2009, which contained the average transaction price per room per night and the total number of rooms sold per transaction.

Next, we discuss the data preparation work that is required. Our work leveraged three types of usergenerated content data:

- On-demand user-contributed opinions through Amazon Mechanical Turk

- Location description based on user-generated geo-tagging and image classification

- Service description based on user-generated product reviews

We first discuss how we leverage Amazon Mechanical Turk to collect information on user preferences for different hotel characteristics. Their responses suggest that these characteristics can be lumped into two groups: location and service characteristics. Once we identify the set of consumer preferences, we use other kinds of user-generated content to infer the external location characteristics, the internal service characteristics, and the textual characteristics of hotel reviews that can influence consumer purchases. For a better understanding of the variables in our setting, we present the data sources, definitions, and summary statistics of all variables in Tables 1 and 2.

\subsection{Identification of Hotel Characteristics using Amazon Mechanical Turk (AMT)}

Our analysis first requires knowledge of those aspects of a hotel that are most important to consumers. These factors determine the aggregate prices of the hotels. For our research, we wanted to avoid imposing 
ourselves the features that we need to consider. Rather, we decided to rely on a survey of potential hotel customers and ask them about the hotel aspects that are important for their purchasing decisions.

We do this through an online survey of users. In order to reach a wide demographic, we decided to rely on the crowd-sourcing marketplace of Amazon Mechanical Turk (AMT, hereafter). AMT is an online marketplace, used to automate the execution of micro-tasks that require human intervention (i.e., cannot be fully automated using data mining tools). Task requesters post simple micro-tasks, known as hits (human intelligence tasks), in the marketplace. The marketplace provides proper control over the task execution, such as validation of the submitted answers, or the ability to assign the same task to several different workers. It also ensures the proper randomization of the assignments of tasks to workers within a single task type. Each user receives a small monetary compensation for completing the task.

For our purposes, our main goal was to have a diversity of consumer opinions. Therefore, before using AMT for our survey, we wanted to ensure that the participants are representative of the overall Internet population. Towards this goal, we constructed a survey, asking AMT workers to give us information about their place of origin and residence, gender, age, education attainment, income, marital status, household size, and number of children. We also asked them about the time that they spend every week on AMT, the amount of work that they complete, the payment they receive, and their reasons for participating on AMT. To ensure that the results were not accidental, we conducted the survey multiple times, once every month. The results of the surveys were consistent over time, indicating that our findings are robust.

The results of the survey indicated that, contrary to popular perception, most of the workers are based in the United States. Typically, $70 \%-80 \%$ of the workers mark the United States as the country of residence. Overall, the population of the workers matched quite nicely the overall population of Internet users. More than $60 \%$ of the workers had university education, and more than $15 \%$ of them had graduate degrees, indicating that the AMT survey participants are more educated than the average Internet user in the US. We also noticed that the age of the workers vary widely but with an overrepresentation of young ages (21-30). Since the participants are comparatively younger compared to the overall Internet population, their income levels were lower, and they had smaller families. Overall, despite some differences, we see that the AMT population is generally representative of the overall US Internet population and more representative than surveys conducted using only locally available participants. ${ }^{3}$

We also asked the AMT workers about their previous experiences with visits to and hotel reservations from Travelocity.com. We found that $92.5 \%$ of workers specified that they have visited the website of Travelocity before, and 55\% specified that they have made hotel reservations through it.

\footnotetext{
${ }^{3}$ In Appendix E, we provide the exact analysis of the survey and a comparison of the demographics, with the demographics of US Internet users, according to the data provided by ComScore. To compensate for the differences in the population, we also stratified the responses from the sample based on demographics, and placed appropriate weights on the responses in order for the results to match the composition of the US Internet user population.
} 
Based on these findings, we use AMT workers as the population to survey to find what hotel characteristics are important for consumers when they make their purchase decisions. As part of our survey, we asked 100 anonymous AMT users the following open-ended question: what are the hotel characteristics that you consider important when choosing a hotel? We grouped and coded the results of the given answers (Table 1 summarizes the identified features) and identified two broad categories of hotel characteristics:

1. Location-based hotel characteristics (such as "Near a beach," "Near a waterfront (lake/river)," "Near public transportation," and "Near downtown")

2. Service-based hotel characteristics (such as "Hotel class," "Quality of service," "Number of internal amenities")

Next, we describe how we use consumer-generated content to collect information about the variables that are either too difficult to collect otherwise (e.g., density of shops around the hotel), or are likely to be very subjective (e.g., "quality of service").

\subsection{Extraction of Location Characteristics using Social Geotagging and Image Processing}

For the location-based characteristics, we combine user-generated content with automatic techniques, to be able to scale our data collection and generate data sets that are comprehensive at the national and even international level (i.e., tens or even hundreds of thousands of hotels). A first, automatic approach is to use a service like the Microsoft Virtual Earth Interactive SDK, which enables us to compute location characteristics like "Near restaurants and shops" for a given hotel location on a map. Using the automatic API from the Microsoft, we can automatically perform such local search queries.

However, the presence of a characteristic like "Near a beach," or "Near downtown" cannot be retrieved by existing mapping services. To measure such characteristics, we use a combination of usergenerated geo-tagging and automatic classification of satellite images of areas near each hotel in our dataset.

Social GeoTagging and AMT-based tagging: The concept of geo-tagging has been popularized lately by photo sharing websites, in which users annotate their photos with the exact longitude and latitude of the location. The concept has been extended and is now used in "wiki"-style websites, where users annotate maps with various types of annotations such as "bridge," "lake," "park" and other similar tags. In our study, we extracted the location characteristics "Near public transportation," "Near a beach" and "Near the downtown" via the site Geonames.org. For the characteristics "Near a lake/river" and "Near the interstate highway," we extracted the features using on-demand annotations from a set of workers from AMT. Such geo-tagging and on-demand annotations enable us to generate a richer description of the location around each hotel, using features that are not directly available through existing mapping services..

Image Classification: However, no matter how comprehensive the tagging is, there can be locations that are not yet tagged by users. Therefore, we need ways to leverage the tag database, and allow for the 
automatic tagging of areas that lack tags. For this, we use automatic image classification techniques of satellite images to tag location features that can influence hotel demand. Consider, for example, the case where we are trying to automatically identify whether a hotel is located "Near a beach," or "Near downtown." Towards this, we extracted hybrid satellite images (sized $256 \times 256$ pixels) using the Visual Earth Tile System ${ }^{4}$, for each of the (thousands) of hotel venues located in the US, with four different zoom levels for each. These $4 \times 1497$ images were used to extract information about the surroundings of the hotel, through image classification and human inspection using AMT.

To automatically tag satellite images, we first needed to train our classification model. As a "training set," we used information from two sources: (i) locations tagged by users on a social tagging site such as Geonames.org or (ii) locations annotated by users on AMT. We built the image classifiers as follows: First, we randomly selected a set of 121 hotels and requested five AMT users to label each example according to its corresponding satellite images from four different zoom levels. The labelers answered whether there is a beach in the image, or whether the image is that of a downtown area. We applied a simple majority voting method to make the final decision from the multi-labels of the example. Second, we trained an SVM classifier on this dataset and used the trained SVM classifier to classify the images that corresponded to the remaining hotels. Prior work has shown that non-parametric classifiers, such as Neural Networks, Decision Trees, and Support Vector Machines (SVM) provide better results than parametric classifiers in complex landscapes (Lu and Weng 2007). Therefore, we tested various non-parametric classification techniques. These include (i) Decision Trees, which are widely used for training and classification of remotely sensed image data (due to their ability to generate human interpretable decision rules and its speed in training and classification), and (ii) Support Vector Machines (SVM), that are highly accurate and perform well for a wide variety of classification tasks (Fukuda and Hirosawa 2001).

We conducted a small study to examine the performance of the classifier out-of-sample data. We classified the out of sample images using AMT; our results illustrated that our SVM classifier had an accuracy of $91.2 \%$ for the "beach" image classification and $80.7 \%$ for the "downtown" image classification. We also used the $\mathrm{C} 4.5$ algorithm for the classification, and noticed an accuracy increase for "Near a beach" and a decrease for "Near downtown." The main reason for this is that "beach" images often contain a "sand strip," together with an "ocean margin" well distributed in density. This typically provides more stable and distinct textural information for the "beach" images, thus making them easier to distinguish.

\footnotetext{
${ }^{4}$ http://msdn2.microsoft.com/en-us/library/bb259689.aspx
} 


\subsection{Extraction of Service Characteristics using Consumer Reviews}

We used two broad characteristics in the category of service-based characteristics: hotel class and number of internal amenities. "Hotel class" is an internationally accepted standard ranging from 1-5 stars, representing low to high hotel grades. "Number of internal amenities" is the aggregation of hotel internal amenities, such as "bedroom quality" (1 bedroom, 2 bedroom etc), "hotel staff," "food quality," "bathroom amenities" and "parking facility." We extracted this information from the Tripadvisor.com website using fully automated parsing. ${ }^{5}$ Since hotel amenities are not listed explicitly on the Tripadvisor.com website, we retrieved them by following the link provided on the hotel web page, which directs the user to one of its cooperating partner websites (i.e., Travelocity.com, Orbitz.com, Expedia.com, Priceline.com, or Hotels.com).

\subsection{Extraction of Textual Quality of Reviews}

We collected customer reviews from Travelocity.com. In order to consider the indirect influence of "word-of-mouth," we also collected reviews from a neutral, third party site - the Tripadvisor.com website, which is the world's largest online travel community. We collected all available online reviews and reviewers' information up to January 31, 2009 (the last date of transactions in our database).

Consistent with prior work, we use the total number of reviews and the numeric reviewer rating to control for word-of-mouth effects. In addition, given that the actual quality of reviews plays an important role in affecting product sales, we looked into two text style features: "subjectivity" and "readability." Both of them can influence consumers' purchase decisions (Ghose and Ipeirotis 2010). To capture the review textual style comprehensively, we used a multiple-item method for subjectivity and readability. We included two sub-features for subjectivity and five sub-features for readability, each of which measures the review text style.

We observed that there are two types of reviews, from the stylistic point of view. There are reviews that list "objective" information, listing the characteristics of the hotel, and giving an alternate description that confirms (or rejects) the description given by the hotel. The other types of reviews are those with "subjective," sentimental information, in which the reviewers give a very personal description of the hotel, and give information that, typically, does not appear in the official description of the hotel.

We distinguished the extent of "subjective assessments" in the reviews by deriving a review-level numerical score for the degree of subjectivity. More specifically, we used the methods from Ghose and

\footnotetext{
5"Fully automated parsing" refers to the approach used to collect information from a website. Technically, we built a "crawler" that first saves to the local computer all the information from the web pages on that website. Then the crawler parses the saved web page files one at a time in an automated fashion using a pre-coded computer program on the local machine.
} 
Ipeirotis (2010) who build on the methods in Pang and Lee (2004). In particular, objective information is considered the information that also appears in the hotel-provided description, and subjective is everything else. To infer the probability of review subjectivity, we trained a classifier by using as "objective" documents the hotel-generated descriptions from the websites of Travelocity and TripAdvisor. We then randomly retrieved 1000 reviews to construct the "subjective" examples of the training set. ${ }^{6}$ After constructing the classifiers, we used the resulting classification models in the remaining, unseen reviews. Instead of classifying each review as subjective or objective, we instead classified each sentence in each review as either "objective" or "subjective," keeping the probability of being subjective for each sentence. By doing so, we were able to acquire a subjectivity confidence score for each sentence in a review, hence deriving the mean and standard deviation of this score as the subjectivity measurements for that review. These numerical scores are able to distinguish how likely a review contains subjective assessments as opposed to objective descriptions.

We also look into the impact of "Readability," which is a proxy for the difficulty faced by people when reading online reviews. Past research has shown that easy-reading text improves comprehension, retention, and reading speed, and that the average reading level of the US adult population is at the eighth grade level (White 2003). Specifically, for each hotel, we collected all existing reviews to examine the average number of characters per review, average number of syllables per review, average number of spelling errors per review, and the average length of the sentence as a "Complexity" measurement (total number of characters divided by the total number of sentences). To avoid idiosyncratic errors peculiar to a specific readability metric, we computed a set of metrics for each review. Specifically, we computed the following: Automated Readability Index, Coleman-Liau Index, Flesch Reading Ease, Flesch-Kincaid Grade Level, Gunning and SMOG. For brevity, we only show results with SMOG Index in the paper although all the other readability measures yield similar results.

Furthermore, previous studies have shown that the social identity information of reviewers in an online community shapes community members' judgment of the products. In other words, the prevalence of reviewer disclosure of identity information is associated with changes in product sales (Forman et al. 2008). Therefore, consistent with prior work, we include the characteristic that captures the level of reviewers' disclosure of their identity information - "real name or location." More specifically, this binary characteristic describes whether or not a reviewer had revealed her real name or location information on the reviewer profile page of Travelocity and Tripadvisor.

In sum, there are 5 broad types of characteristics in this category: (i) total number of reviews, (ii) overall review rating, (iii) review subjectivity (mean and variance), (iv) review readability (the number of

\footnotetext{
${ }^{6} \mathrm{We}$ conducted the training process by using a 4-gram Dynamic Language Model classifier provided by the lingpipe toolkit. "Lingpipe" is a tool kit provided online for processing text using computational linguistics (More information can be found at http://alias-i.com/lingpipe/).
} 
characters, syllables, and spelling errors, complexity and SMOG Index), and (v) the disclosure identity information by the reviewer.

\section{Model}

In this section, we will discuss how we develop our random coefficient structural model and describe how we apply it to empirically estimate the distribution of consumer preferences towards different hotel characteristics in our setting.

\subsection{Random Coefficient Model Setup}

Our model is motivated directly by the model in Song (2010), where the author proposed a hybrid discrete choice model of differentiated product demand. While Song (2010) had one random coefficient on price, we have multiple random coefficients on prices as well as hotel characteristics. Note that this hybrid model is a combination of the BLP (1995) and the PCM (2007) approaches. It is called a hybrid model because it resembles the random coefficient logit demand model in describing a brand choice (BLP 1995) and the pure characteristics demand model in describing a within-brand product choice (PCM 2007). This is basically a discrete choice model of differentiated product demand in which product groups are horizontally differentiated while products within a given group are vertically differentiated conditional on product characteristics. These two types of differentiation are distinguished by a group-level "taste shock," which is assumed to be distributed i.i.d. with a Type I extreme-value distribution. This taste shock represents each consumer's specific preference towards a product group that is not captured by observed or unobserved product characteristics. Song (2010) refers to a product group that contains vertically differentiated products a "brand." This hybrid model identifies preference for product characteristics in a similar way as the PCM. The main difference that the hybrid model compares products of each brand on the quality ladder separately, while the PCM compares all products on it at the same time. Hence, the quality space is much less crowded in the hybrid model. ${ }^{7}$

In our context, a hotel "travel category" represents a "brand" and the hotels within each "travel category" represent "products." In particular, the market share function of hotel $j^{k}$ within travel category $k$ can be written as the product of the probability that travel category $k$ is chosen and the probability that hotel $j^{k}$ is chosen given that travel category $k$ is chosen. The former probability is similar to the choice probability in BLP, and the latter to that of the PCM..

\footnotetext{
${ }^{7}$ This hybrid model provides more efficient substitution patterns according to its basic assumptions and model foundations. As Song (2009) describes, it distinguishes two types of cross substitutions: the within-travel category substitution and the between-travel category substitution. The former is confined to hotels within the same travel category and has the same substitution pattern as in the PCM. The latter determines the substitution pattern for hotels in different travel categories and has a similar pattern as in BLP but with a distinct difference. That is, impact of a change (in price or availability) on other travel categories is confined to hotels of similar quality. As a result, a hotel will have fewer substitutes in our model than in the BLP model.
} 
We define a consumer's decision-making behavior as follows. A consumer needs to locate the hotel whose location and service characteristics best matches her travel purpose. For instance, if a consumer wants to go on a romantic trip with a partner, she would be interested in the set of hotels that are located close to a beach, downtown with amenities like nightclubs, restaurants, etc. She is also aware that hotels specializing in the "romance" category are more likely to satisfy such location and service needs. Each hotel can belong to one of the following eight types of "travel categories:" Family Trip, Business Trip, Romantic Trip, Tourist Trip, Trip with Kids, Trip with Seniors, Pet Friendly, and Disability Friendly. ${ }^{8}$ To capture the heterogeneity in consumers' travel purpose, we introduce an idiosyncratic "taste shock" at the travel category level. This is similar to the product-level "taste shock" in the BLP (1995) model.

Each travel category has a hotel that maximizes a consumer's utility in that category. We refer to this as the "best" hotel in that category. To find the "best" hotel within each travel category, we use the pure characteristic model (PCM) proposed by Berry and Pakes (2007). The PCM approach is able to capture the vertical differentiation amongst hotels within the same travel category. A rational consumer chooses a travel category if and only if her utility from the best hotel in that category exceeds her utility from the best hotel in any other travel category. Thus, in our model, the utility for consumer $i$ from choosing hotel $j$ with category type $k$ in market $t$ can be represented as illustrated in Equation (1):

$$
u_{i j k_{t}}=X_{j^{k}} \beta_{i}-\alpha_{i} P_{j^{k}}+\xi_{j^{k}}+\varepsilon_{i t}^{k}
$$

Where: $i$ represents a consumer, $j^{k}$ represents hotel $j$ with travel category type $k(1 \leq k \leq 7)$, and $t$ represents a hotel market. In this model, $\beta_{i}$ and $\alpha_{i}$ are random coefficients that capture consumers' heterogeneous tastes towards different observed hotel characteristics, $X$, and towards the average price per night, $P$, respectively. $\xi$ represents hotel characteristics unobservable to the econometrician. $\varepsilon_{i t}^{k}$ with a superscript $k$ represents a travel category-level "taste shock." Note that in our model the travel categorylevel shock is independently and identically distributed across consumers and travel categories, consistent with Song (2010). ${ }^{9}$

We define a "market" as the combination of "city-week." Correspondingly, the market share for each hotel is calculated based on the number of rooms sold for that hotel in that city during that week divided by

\footnotetext{
${ }^{8}$ Each travel category is defined and chosen according to the information gleaned from the website of TripAdvisor. TripAdvisor allows reviewers to specify their main trip purpose (travel category) while posting a review. We have data on all the hotel reviews posted by users for a given hotel right from the time the first review was posted till the last date of our transaction dataset (February 2009). A hotel is classified into a specific travel category based on the most frequently mentioned travel purpose by the reviewers for that hotel. Hence, each hotel belongs exclusively to a travel category.

${ }^{9}$ Besides our model which incorporates a travel category level taste shock, there are at least three other plausible modeling approaches in this context: (i) a model with only a hotel-level taste shock, resembling the BLP (1995) approach, (ii) a model with both travel-category and hotel-level taste shocks, with travel category at the top hierarchy, resembling the nested logit model, and (iii) a model with no taste shocks either at the travel category or hotel level, resembling the PCM (2007) approach. We have estimated all these models and found that our hybrid model provides the best performance in both precision and deviation. Details are provided in Section 5.3.
} 
the total number of rooms sold from all hotels in that city during that week. For robustness check, we also tried the combination of "city-night," and tried "revenue" instead of "room units" as the basis for market share calculation. Meanwhile, regarding the "size" of market, we chose two different definitions, which lead to two different definitions of "outside good." (1) In our main estimation, we applied the similar idea as in most demand estimation literatures (e.g., Berry, S et.al 1995, Song 2010) by estimating the potential consumptions in a market. For example, we defined the potential market size as proportional to the total number of hotels in a certain market ${ }^{10}$. Under such definition, the "outside good" is defined as "no purchase from the current choice set." (2) Alternatively, since our main dataset comes from two major sources: Travelocity-generated transaction data and TripAdvisor review data. The dataset we used in our analysis is the set of hotels at the intersection of the two sources. This means that the hotel choice set for each market includes those hotels that not only have a transaction generated via Travelocity, but also have available information on user-generated reviews on TripAdvisor. Since not every hotel that has a Travelocitygenerated transaction is listed on the TripAdvisor website, we define our "outside good" as the set of hotels that are listed in the original Travelocity transaction data, but not listed on the TripAdvisor website. Furthermore, we also tested other ways of varying the market size. For example, we applied similar ideas as in Song (2007), by increasing or decreasing the total size for each market by $20 \%$. Based on all the work above, we found that in our data different definitions for market size yield qualitatively the same results.

Due to the computational complexity and data restriction, estimating a unique set of weights for each consumer is intractable. To make this model tractable, we made some further assumptions about $\beta_{i}$ and $\alpha_{i}$ One is to assume that these weights are normally distributed among consumers, i.e., $\beta_{i} \sim\left(\beta_{i} \mid \bar{\beta}, \sigma_{\beta i}\right)$ and $\alpha_{i} \sim\left(\alpha_{i} \mid \bar{\alpha}, \sigma_{\alpha i}\right)$. Our goal is then to estimate the means $(\bar{\beta}, \bar{\alpha})$ and the standard deviations $\left(\sigma_{\beta i}\right.$, $\sigma_{\alpha i}$ ) of these two distributions. The means correspond to the set of coefficients on hotel characteristics and on hotel price, which measures the average weight placed by the consumers. The standard deviations provide a measure of the extent of consumer heterogeneity in those weights.

Furthermore, we notice that these heterogeneities result from particular demographic attributes of consumers. For example, the variance in the price coefficient is very likely a result of differences in incomes among the consumers. Therefore, we make additional assumptions about the standard deviations: $\sigma_{\alpha i} \sim \alpha_{I} I_{i}$, where $I_{i}$ represents the income whose distribution can be learned from the consumer demographics; $\sigma_{\beta i} \sim \beta_{v} v_{i}$, where $v_{i} \sim N(0,1)$ represents some random factor that will influence people's preferences towards individual hotel characteristics.

Therefore, we have the following two forms for the consumer-specific coefficients $\alpha_{i}$ and $\beta_{i}$ :

$$
\alpha_{i}=\bar{\alpha}+\alpha_{I} I_{i} \quad \text { and } \quad \beta_{i}=\bar{\beta}+\beta_{v} v_{i} .
$$

We then rewrite our model as follows:

$$
u_{i j k_{t}}=\delta_{j^{k} t}+X_{j^{k} t} \beta_{v} v_{i}-\alpha_{I} I_{i} P_{j^{k} t}+\varepsilon_{i t}^{k},
$$

\footnotetext{
${ }^{10}$ We acquired the total number of hotels in each market via TripAdvisor.
} 
Where: $\delta_{j^{k} t}=X_{j^{k} t} \bar{\beta}-\bar{\alpha} P_{j^{k} t}+\xi_{j^{k} t}$, represents the mean utility of hotel $j$ with category type $k$ in market $t . \beta_{v}$ and $\alpha_{l}$ are the parameters to be estimated.

\subsection{Estimation}

We now discuss how we identify the values for the parameters. As mentioned in the previous subsection, our goal here is to estimate the mean and variance of $\beta_{i}$ and $\alpha_{i}$. We apply methods similar to those used in Berry and Pakes (2007) and Song (2010). In general, with a given starting value of $\theta_{0}=\left(\alpha_{I}^{0}, \beta_{v}^{0}\right)$, we look for the mean utility $\delta$, such that the model predicted market share is equal to the observed market share. From there, we form a GMM objective function using the moment conditions in that the mean of unobserved characteristics is uncorrelated with the instrumental variables. Based on this, we identified a new value of $\theta_{1}=\left(\alpha_{I}^{1}, \beta_{v}^{1}\right)$, which will be used as the starting point for the next round iteration. This procedure is repeated until the algorithm finds the optimal value of $\theta$ that minimizes the GMM objective function. More specifically, we conduct the estimation in three stages.

\section{(i) Calculating Market Shares}

In order to calculate the market share for a particular hotel, we need to know: (1) the size of a certain consumer segment, and (2) the probability of this hotel being chosen by that consumer segment. By multiplying the two, we are able to derive the overall market share. The mathematical details for the derivation are provided in Appendix D.

\section{(ii) Solving Mean Utility $\delta$}

With the market share being derived, we can then identify the mean utility $\delta$ by equating the estimated market share to the observed market share conditioning on a given $\theta=\left(\alpha_{I}, \beta_{v}\right)$. As we can see, this problem can be essentially reduced to a procedure of solving a system of nonlinear equations. In our case, there are $\sum_{k=1}^{K} J^{k}$ nonlinear equations (where $J^{k}$ is the total number of hotels within travel category type $k$ ) and $\sum_{k=1}^{K} J^{k}$ unknown variables ( $\delta$ being a $\sum_{k=1}^{K} J^{k}$ dimension vector). To find a solution, we apply Newton-Raphson method suggested by Song (2010), where this method was shown to work well when the number of products per market is up to 20 . To guarantee the robustness of the results when the number of products is larger than 20 , we tried different initial values in the iteration. The final solution was consistent across different initial values. In practice, this approach locates the closest solution for our settings, while the iteration procedure provides a very close form to locate the roots rapidly and stably.

(iii) Solving $\alpha_{I}$ and $\beta_{v}$

To account for the endogeneity of price, we use a GMM estimator and form an objective function by interacting the unobservable parameter, $\xi$, with a set of instrumental variables. By minimizing the GMM 
objective function, we determined the proper set of $\alpha_{I}$ and $\beta_{v}$. We use the new $\alpha_{I}$ and $\beta_{v}$ as the starting points to recalculate the market share in Step (1) and solved for the new mean utility in Step (2). This entire procedure iterates until the algorithm finds the optimal combination of $\alpha_{I}, \beta_{v}$ and $\delta .{ }^{11}$

In our case, we use average price of the "same-star rating" hotels in the other markets as an instrument for price, similar to the approach of Hausman et al. (1994). We have tried four other sets of instruments. First we follow Villas-Boas and Winer (1999) and use lagged prices as instruments in conjunction with Google Trends data. The lagged price may not be an ideal instrument since it is possible to have common demand shocks that are correlated over time. Nevertheless, common demand shocks that are correlated through time are essentially trends. Our control for trends using search volume data thus should alleviate most, if not all, such concerns. Second, we have used employee wage data from BLS as a "cost side" instrument using the category of "Accommodation." The assumption here, like in other papers that use such cost-side instruments is that hotel employee wages are correlated with hotel room prices but uncorrelated with factors that are reflected in the unobserved characteristics term (see for example, Chintagunta et al. 2005). Third, we have also tried region dummies as proxies for the cost (e.g., the cost of transportation, labor, etc.) as suggested by Nevo (2001). Fourth, we have used BLP-style instruments. Specifically, we have used the average characteristics of the same-star rating hotel in the other markets. All these alternate estimations yielded very similar results. The corresponding estimation results using alternative instruments are provided in Table 3 columns 4-7. We did an F-test in the first stage for each of the four sets of instruments. In each case, the F-test value was well over 10, suggesting that our instruments are valid (i.e., the instruments are not weak). In addition, the Hansen's J-Test could not reject the null hypothesis of valid overidentifying restrictions. The detailed estimation algorithm and the discussion for model identification are provided in Appendix E1 and E2. ${ }^{12}$

\subsection{Model Extension (1): Additional Text Features}

So far we have not fully exploited the information about hotel service characteristics from the data, which is embedded in the natural language text of the consumer reviews. For example, the "helpfulness of

\footnotetext{
${ }^{11}$ For our model, the computational time for each call (i.e., the inner loop) to the GMM objective function to solve for the mean utility is around 8 minutes on average. The global parameter search (i.e., the outer loop) by minimizing the GMM objective function takes an average of 20 calls. The total computational time for the estimation is around 3 hours. For the BLP model, the computational time for each call to the GMM objective function to solve for the mean utility is about 3 minutes on average. The global parameter search process takes about the same number of calls (i.e., 20). The total computational time for the BLP estimation is around 40 minutes to 1 hour.

${ }^{12}$ Dube, Fox and Su (2009) note that a theoretical advantage of Newton-type methods, is that they are quadratically convergent when the iterates are close to a local solution (e.g., Kelly 2003 and Nocedal and Wright 2006). To make sure our estimates are reliable, we employed 50 starting points in each run of the estimation. We routinely found that our algorithm were able to identify the same local minimum each time. Moreover, as suggested by Knittel and Metaxoglou (2008), we also tried several alternative optimization algorithms, including (i) direct-search algorithms: e.g., the Nelder-Mead simplex method; (ii) derivative-based algorithms: e.g., the Fletcher-Reeves conjugate gradient method and the vector Broyden-Fletcher-Goldfarb-Shanno (BFGS) method (which is a quasi-Newton method). We found that different algorithms were able to recover consistent structural parameters in our data.
} 
the hotel staff' is a service feature that can be assessed by reading the actual consumer opinions. Towards extracting such information, we build on the work of Hu and Liu (2004), Popescu and Etzioni (2005), Archak et al. (2008), and use a POS (part-of-speech) tagger to identify frequently mentioned nouns and noun phrases, which we consider candidate hotel features. We then cluster these phrases, using WordNet (Fellbaum 1998) and then use a context-sensitive hierarchical agglomerative clustering algorithm (Manning and Schutze 1999) to cluster further the identified nouns and noun phrases into clusters of similar nouns and noun phrases. The resulting set of clusters corresponds to the set of identified product features mentioned in the reviews. For our analysis, we kept the top-5 most frequently mentioned features, which were hotel staff, food quality, bathroom, parking facilities, and bedroom quality. ${ }^{13}$

In the next step, we extract all the evaluation phrases (adjectives and adverbs) that are being used to evaluate the individual service features (for example, for the feature "hotel staff" we extract phrases like "helpful", "smiling", "rude", "responsive", etc) . To measure the meaning of these evaluation phrases, we used Amazon Mechanical Turk to exogenously assign explicit polarity semantics to each word. To compute the scores, we used AMT to create our ontology, with the scores for each evaluation phrase. Our process for creating these "external" scores was done using the methodology of Archak et al. (2008). We asked nine AMT workers to look at the pair of the evaluation phrase together with the product feature, and assign a grade from -3 (strongly negative) to +3 (strongly positive) to the evaluation. This resulted in a set of nine, independently submitted evaluation scores; we dropped the highest and lowest evaluation score, and used the average of the remaining seven evaluations as the externally imposed score for the corresponding evaluation-product phrase pair. As an example, when evaluating "hotel staff", the AMT process resulted in "helpful" having value of 0.9 , "rude" to be -0.5 , "responsive" to be 0.5 , and so on. We should stress that the scoring of the evaluation phrases is only necessary to be done once as the set of hotel features, and the corresponding semantic evaluation phrases are highly unlikely to change over time.

\subsection{Model Extension (2): Interactions with Travel Category}

As discussed previously, by modeling the standard deviations of $\alpha_{i}$ and $\beta_{i}$ (i.e., consumer-specific coefficients towards price and towards hotel characteristics) to be a function of consumer income $\left(\sigma_{\alpha i} \sim \alpha_{I} I_{i}\right)$ and a function of the unobserved consumer characteristic $\left(\sigma_{\beta i} \sim \beta_{v} v_{i}\right)$, respectively, our

\footnotetext{
${ }^{13}$ To select the top 5 features, we first processed all the reviews for each hotel, and extracted text features (i.e., terms) that appeared frequently in the reviews for each hotel. For example, for Hotel A the features extracted based on the reviews for Hotel A can be "bed", "bathroom" and "pool"; for Hotel B the features can be "bed", "bathroom" and "restaurant". Then, we selected the top 5 most frequently extracted features across all hotels. In our example, the features will be "bed" and "bathroom". The top 5 features that we selected in our study covered $80 \%$ of the hotels, which means that for $80 \%$ of the hotels the extracted text features contain these 5 features. While technically possible, we did not consider more textual features because the frequency in which the additional features are mentions drops significantly, and therefore we would not be able to have a robust measurement for these textually-inferred features for a very significant fraction of the hotels in our dataset.
} 
basic model is able to take into account the consumer heterogeneity originated from different income levels as well as from the unobserved consumer attributes. Furthermore, to capture richer effects from consumers' heterogeneous tastes, demographics could potentially be added to the model in a more complex manner. This can be achieved in a similar fashion as in Nevo (2001), by enabling interactions between travel categories and product characteristics.

More specifically, we extend our basic model by assuming that the standard deviations of $\alpha_{i}$ and $\beta_{i}$ are functions of additional consumer-level travel demographics. In our case, we focus on consumer travel purpose. Thus, we have the following two extended forms for the consumer-specific coefficients $\alpha_{i}$ and $\beta_{i}$

$$
\alpha_{i}=\bar{\alpha}+\alpha_{I} I_{i}+\alpha_{T} T_{i} \quad \text { and } \quad \beta_{i}=\bar{\beta}+\beta_{v} v_{i}+\beta_{T} T_{i}
$$

where $T_{i}$ is an indicator vector with identity components representing consumer travel purpose: ${ }^{14}$

$$
T_{i}{ }^{\prime}=\left[\text { Family }_{i} \text { Business }_{i} \text { Romance }_{i} \text { Tourist }_{i} \text { Kids }_{i} \text { Seniors }_{i} \text { Pets }_{i} \text { Disability }_{i}\right] .
$$

For example, if consumer $i$ is on a business trip, then the corresponding travel purpose vector is

$$
T_{i}{ }^{\prime}=\left[\begin{array}{llllllll}
0 & 1 & 0 & 0 & 0 & 0 & 0 & 0
\end{array}\right] \text {. }
$$

Based on this additional assumption, the overall extended model can be thereby rewritten as

$$
u_{i j^{k} t}=\delta_{j^{k} t}+X_{j^{k} t} \beta_{v} v_{i}+X_{j^{k} t} \beta_{T} T_{i}-\alpha_{I} I_{i} P_{j^{k} t}-\alpha_{T} T_{i} P_{j^{k} t}+\varepsilon_{i t}^{k} .
$$

In the next section, we will discuss our empirical results from our basic and extended models.

\section{Empirical Analysis and Results}

Note that a consumer who is searching for hotel reviews on Travelocity or Tripadvisor gets to see a different number of reviews on the pages of each website. While Travelocity.com displays the first five reviews on a page, Tripadvisor.com lists 10 reviews per page. To minimize the potential bias caused by webpage design, since some customers may only read the reviews on the first page, we decided to consider two more alternatives besides our main dataset: Dataset (II) with hotels that have at least five reviews, and Dataset (III) with hotels that have at least 10 reviews. Controlling for brand effect, the estimation results from these three datasets are illustrated in Table 3 columns 2-4. As described previously, we tried several different instruments by using lagged prices with Google Trends, various proxies for marginal costs as well as BLP-style instruments. The corresponding results are in Table 3 columns $5-8 .^{15}$

\footnotetext{
${ }^{14}$ The empirical distribution of $T_{i}$ can be acquired from online consumer reviews and reviewers' profiles. Our robustness test showed that consumers' demographics derived from different online resources stay consistent (JensenShannon Divergence $=0.03$ ).

${ }^{15}$ For normalization purpose, we used the logarithms of "price," "characteristics," "syllables," "spelling errors," "crime rate," "internal amenities," "external amenities" and "review count (both TripAdvisor and Travelocity)" in all the analyses in this paper.
} 
In subsection 5.2, we discuss our robustness tests: (1) using the same model based on different samples using alternative levels of online review data, and (2) using a different model based on the same datasets. Then, in Subsection 5.3, we further discuss the results on model validation by comparing our model with the current competitive ones. In subsection 5.4, we will provide some managerial implications by conducting counterfactual policy experiments. Finally, in subsection 5.5, we will briefly discuss the results from our extended model.

\subsection{Results from the Basic Model}

Location-based characteristics: There are five location-based characteristics, which have a positive impact on hotel demand: "external amenities," "beach", "public transportation," "highway," and "downtown." These characteristics strongly imply that the location and geographical convenience for a hotel can make a big difference in attracting consumers. Hotels providing easy access to public transportation (such as a subway or bus stations), highway exits, restaurants and shops, or easy access to a downtown area, can have a much higher demand. "Beach," also showed a positive impact on demand. It turns out that most beach-based hotels in our dataset were located in the south where the weather typically stays warm even in winter. Therefore, the desirability of a "walkable" beachfront did not reduce even in the winter season (which is the time of our data). ${ }^{16}$

Two location-based characteristics have a negative impact on hotel demand: "annual crime rate" and "lake/river." The higher the average crime rate reported in a local area, the lower the desirability of consumers for staying in a hotel located in that area. This indicates that neighborhood safety plays an important role in the hotel industry. The second location-based characteristic that illustrates a negative impact is the presence of a water body like a lake or a river. This is interesting because one would expect people to choose a hotel near a lake or by a riverside. However, most waterfront-based hotels in our dataset were located in places where the weather becomes extremely cold in the winter months of November to January. Due to the low temperatures, it is likely that a lake or riverfront becomes less desirable for travelers. ${ }^{17}$

To further examine the impact of lake, we collected weather data from the National Oceanic and Atmospheric Administration (NOAA) on the average temperature from 2008/11 to 2009/1 for all cities. Then, we defined 2 dummy variables: "High Temp" which equals to 1 if the average temperature is higher

\footnotetext{
${ }^{16}$ In addition, we also considered "Airport" and "Convention centers". The estimation results are consistent with our current results, but the coefficients for the two characteristics are statistically insignificant.

${ }^{17}$ In addition, some traveler reviews commented on the presence of mosquitoes in areas near a lake.
} 
than 50 degree, and "Low Temp" which equals to 1 if the average temperature is lower than 40 degree. $^{18}$ We interact "High Temp" and "Low Temp" separately with "Lake" in our model. The results showed that the interaction of "Low Temp" with "Lake" has a significantly negative effect. This supports our earlier argument. Meanwhile, the interaction of "High Temp" with "Lake" showed a significantly positive effect, suggesting that warmer weather may help the lake area to attract more visitors. As a robustness check, we did the similar analysis for "Beach" conditional on high and low temperatures. The results showed similar trend. The corresponding estimation results considering the interactions with the temperature are shown in column 9 in Table 3.

Service-based characteristics: Both "class" and "amenity count" has a positive impact on hotel demand. Hotels with a higher number of amenities and higher star-levels have higher demand, controlling for price. "Reviewer rating" also has a positive association with hotel demand. With regard to the "number of reviews," we find a positive sign for its linear form while a negative sign for its quadratic form. This indicates that the economic impact from the customer reviews is increasing in the volume of reviews but at a decreasing rate, as one would expect.

Textual quality of reviews: The textual quality and style of reviews demonstrated a statistically significant association with demand. All the readability and subjectivity characteristics had a statistically significant association with hotel demand. Among all the readability sub-features, "complexity," "syllables" and "spelling errors" had a negative sign and, therefore, have a negative association with hotel room demand. This implies that reviews higher readability characteristics (short sentences and less complex words), and reviews with fewer spelling errors have a positive association with demand. On the other hand, the sign of the coefficients on "characters" and "SMOG index" is positive, implying that longer reviews that are easier to read have a positive association with demand. ${ }^{19}$ These results indicate that consumers can form an image about the quality of a hotel by judging the quality of the (user-generated) reviews.

Both "mean subjectivity" and "subjectivity standard deviation" turned out to have a negative association with demand. This implies that consumers prefer reviews that contain objective information (such as factual descriptions of rooms) relative to subjective information. With respect to the "subjectivity standard deviation," our findings suggest that people prefer a "consistent objective style" from online customer reviews compared to a mix of objective and subjective sentences. The last review-based characteristic was "disclosure of reviewer identity." This variable demonstrated a positive association with hotel demand. This result is consistent with previous work (Forman et al. 2008), which suggested that the

\footnotetext{
${ }^{18}$ We tried other combinations to classify High vs. Low temperatures ( $>=70$ degrees as High and $<=30$ degree as Low (ii) $>=60$ degrees as High and $<=20$ degrees as Low) but they all yielded qualitatively similar results.

${ }^{19}$ To alleviate any possible concerns with multi-collinearity between $S M O G$ and Syllables, we re-estimate our model after excluding the SMOG index variable. There was no change in the qualitative nature of the results across the different datasets.
} 
identity information about reviewers in the online travel community can shape positively community members' judgment towards hotels. "Price" has a negative sign, which is as expected.

Quantitative Effects of location-, service- and review-based hotel characteristics: Besides the above qualitative implications, we also quantitatively assess the economic value of different hotel characteristics. More specifically, we examined the magnitude of marginal effects on hotel demand for the location-, service- and review-based hotel characteristics. The presence of a beach near the hotel increases demand by $18.00 \%$ on an average. In contrast, a location near a lake or river decreases demand by $12.94 \%$. Meanwhile, easy access to transportations and highway exits increase demand by $18.09 \%$ and $7.99 \%$, separately. Presence of a hotel near downtown increases demand by $4.70 \%$. With regard to service-based characteristics, a 1-star improvement in hotel class leads to an increase in demand by $3.77 \%$ on average. Moreover, the presence of one more internal or external amenity increases demand by $0.06 \%$ or $0.08 \%$, respectively. Demand decreases by $0.27 \%$ if the local crime rate increases by one unit.

With regard to the review-based characteristics, we found that the SMOG index (which represents the readability of the review text), has the highest marginal influence on demand on an average. A one level increase in SMOG index of reviews is associated with an increase in hotel demand by $8.95 \%$ on an average. A one unit increase in the number of characters is associated with an increase in hotel demand by $0.11 \%$, whereas a one unit increase in the number of spelling errors, syllables or in complexity is associated with a decrease in hotel demand by $1.44 \%, 0.45 \%$, and $1.18 \%$, respectively. In terms of review subjectivity, a 10 percent increase in the average subjectivity level is associated with a decrease in hotel demand by $1.72 \%$; a 10 percent increase in the standard deviation of subjectivity will reduce demand by $4.94 \%$. Finally, a 10 percent increase in the reviewer identity-disclosure levels is associated with an increase in hotel demand by $0.63 \%$.

Note that the estimation results from the three datasets are highly consistent. In general, all the coefficients illustrate a statistical significance with a p-value equal to or below the $5 \%$ level across all three datasets. Moreover, a large majority of variables present a high significance with a p-value below the $0.1 \%$ level.

\subsection{Robustness Checks}

To assess the robustness of our estimation model and results, we report two additional groups of tests.

(i) Robustness Test I: Use the same model based on alternative sample splits.

We considered three alternative datasets: Dataset (IV) containing hotels with at least one review from Tripadvisor.com, Dataset (V) containing hotels with at least one review from Travelocity.com, and Dataset (VI) containing hotels with at least one review from both. The results are in Appendix A, Table A1. We found that the coefficients from the estimations are qualitatively very similar to our main results. Moreover, similar to those in the main results, most variables in the robustness tests also illustrate statistical 
significance at or below the 5\% level or stronger. Thus, our estimation results, based on the hybrid random coefficient model, are quite consistent across different datasets.

(ii) Robustness Test II: Use an alternative model based on the same datasets.

To examine the robustness of the results from our model, we conducted another group of tests using an alternative model that has been widely used in the industrial organization and marketing literature, the random coefficient logit model, or BLP (Berry et al. 1995). As mentioned in Section 4, the key difference between the BLP approach and our model is that BLP introduces a demand "taste shock" at each product level (in our case, hotel), rather than at a group level (in our case, the travel category), as in our model. Consequently, the substitution space for BLP is different in the sense that BLP does not distinguish between the two types of cross substitutions - the "within-travel category" and "between-travel category." Rather, it would treat all hotels as possible substitutes. We added two sets of dummy variables, one for brand and the other for travel category. We conducted the same set of estimations based on Datasets (I) (VI).

The results are in columns 2-7 in Table A2 in Appendix A. In addition to an alternate specification with homogeneous coefficients on the travel category dummies, we further considered consumers' heterogeneous preferences by assigning random coefficients to these dummies. The corresponding results are shown in the last column in Table A2 in Appendix A.

We find that the estimation results from the BLP model are consistent with our main estimation results using the hybrid model. Specifically, the coefficients from the BLP estimation demonstrate three trends: (i) they have the same signs compared to our main results from the hybrid model, which means that the economic effects are consistent in direction, (ii) they exhibit lower levels of statistical significance, compared to our main results, and (iii) the magnitude of these coefficients is generally higher compared to our main results. These three trends are also very consistent with the findings in Song (2010). In the next subsection, our model validation results further confirm this finding.

\subsection{Model Comparison}

For model comparison purposes, we estimated three baseline models: the BLP model, the PCM model and the nested logit model with travel category at the top hierarchy. Based on the previous study by Steckel and Vanhonacker (1993), we randomly partitioned our main sample Dataset (I) into two parts: a subset with $70 \%$ of the total observations as the "estimation sample," and a subset with $30 \%$ of the total observations as the "holdout sample." To minimize any potential bias from the partition procedure, we performed a 10-fold cross-validation. We conducted this validation process for our random coefficient model and the three baseline models. Furthermore, to examine the model's ability to capture a deeper level of consumer heterogeneity, we compared an extended version of our model with an extended version of the BLP model when incorporating additional interaction effects (i.e., travel purpose interacted with price and hotel 
characteristics). Finally, to examine the significance of the UGC-based, the location-based and the servicebased hotel characteristics, we compared with the original model fit by using the same hybrid model but excluding the UGC, location, and service variables, separately. We have done the above work for both insample and out-of-sample comparisons. The results are provided in Table B1 to B6 in Appendix B. ${ }^{20}$

The results showed that a model that conditions on UGC variables significantly improves the model predictive power. With respect to out-of-sample RMSE, the model fit improves by $35.80 \%$ when add the UGC variables. Similar trends in improvement in our model fit occur with respect to the other two metrics, MSE and MAD in both in-sample and out-of-sample analyses.

Our out-of-sample results in Table B4 illustrate that our model improves by $10.51 \%$ in RMSE compared to the BLP model with no random coefficients on travel category dummies. This number becomes 53.04\%, 61.65\%, and 8.46\% with respect to the PCM, the Nested Logit model, and the BLP model with random coefficients on travel category dummies, respectively. Thus, our model provides the best overall performance in both precision (i.e., RMSE, MSE) and deviation (i.e., MAD) of the predicted market share. The nested logit model presents the worst performance in the predictive power. Moreover, as illustrated in Table B5, when incorporating interaction effects, although both models show improvement in predictive power, the extended hybrid model performs much better than the extended BLP model.

From Table B6 we find that by including the UGC, location-based, and service-based variables, our model fit improves by $35.80 \%, 55.06 \%$, and $52.43 \%$ in RMSE. Similar trends in improvement in our model fit occur with respect to the other metrics, MSE and MAD. Therefore, our results suggest that the model predictive power will drop the most if we were to exclude the location-based variables from our model, followed by the service-based variables, and finally followed by the UGC variables.

This strongly indicates that location- and service-based characteristics are indeed the two most influential factors for the hotel demand. We also find similar trend from the in-sample model comparison results.

\subsection{Counterfactual Experiments}

A key advantage of structural modeling is its potential for normative policy evaluation. To measure explicitly the economic impact of strategic policies, we conducted various counterfactual experiments. Specifically, we simulated the following three sets of scenarios.

(i) Counterfactual Experiment I: Marginal effects under different location environments.

\footnotetext{
${ }^{20}$ With regard to the unobserved characteristics required for out-of-sample prediction using the hybrid, BLP and PCM models, we applied the same method as suggested in Athey and Imbens (2007). We drew the unobserved characteristics for the "holdout sample" randomly from the marginal distribution of unobserved characteristics estimated from the "estimation sample". This method has also been used in the Marketing literature. See for example, Nair, Dube and Chintagunta (2005) who infer the structural error for the "hold out" sample from the marginal distribution of the structural error across different markets derived from the "estimation" sample.
} 
In this experiment, we aimed at examining the robustness for the rank order of marginal effects of the location features in different location environments (e.g., areas with no beach or no transportation). We first generated 6 derivative samples, by assuming each of the following 6 location features to be absent, beach, downtown, highway, lake, transportation, and external amenities, one at a time. Second, we re-computed the corresponding utilities for hotels, assuming the corresponding value for the absent location feature to be zero. Then, we re-estimated the marginal effects for the remaining features given the updated utilities. Our finding showed that the marginal effects for the remaining location features preserve the order from our original estimates. This strongly suggests that the rank order of economic significance of the location features is robust over different location environments.

(ii) Counterfactual Experiment II: Effects of price cut under different location environments.

To examine how pricing policy change will affect hotel demand under different location environments, we conducted the second set of counterfactual experiments. First, we consider the same 6 different location environments as in the experiment I, by assuming each of the 6 location features to be absent one at a time. Then, we assumed a price cut by $20 \%$ for each environment and examine the demand change. Our finding showed that the increase of hotel demand is the lowest in areas with no highway compared to others. This low price elasticity suggests that in such areas consumers tend to be less sensitive to price cut.

Furthermore, we consider two additional types of location feature combinations: (1) Beach and highway (which represents the typical west/south coast setting), and (2) Downtown, transportation and external amenities (which represents the typical big city setting). Correspondingly, we generated two derivative datasets by assuming all other location features that are not in the combination to be absent for each case. Again, we re-computed the utilities and re-estimated the model. Results show that the increase in demand is $21 \%$ lower in big city setting than that in coastline setting. Consumers tend to react much less sensitively to hotel price in big cities. This strongly indicates that price change in big cities may not be an effective strategy in adjusting hotel demand, compared to that in coastline areas.

(iii) Counterfactual Experiment III: Effects of price cut on substitution pattern.

In the third set of experiments, we looked into how price change in one type of hotels will affect the demand for other types of hotels. Specifically, we focused on hotels with different star ratings.

We assumed a price cut by $20 \%$ for all 4 -star hotels. By doing so, we tried to find out what are the demand changes for the 5-, 3-, 2-, 1-star hotels. Our results showed that under the experimental setting, the demand for 4-star hotels will increase $2.79 \%$, while the demand for hotels from all other classes will decrease. Among all of them, the demand for 5-star hotels drops the most with a rate of $5.13 \%$, followed by 3 -star hotels with a rate of $3.73 \%$. The negative impacts on the demand for 1-star and 2-star hotels are relatively smaller, with a rate of $2.76 \%$ and $2.50 \%$, respectively. Meanwhile, we also conducted similar 
analyses for hotels from other classes. For example, by assuming a $20 \%$ price cut for the 3 -star hotels, we found that the demand for 3-star hotels will increase by $2.68 \%$. As a result, the demand for 4-star and 2-star hotels will drop the most, with a rate of $4.94 \%$ and $4.81 \%$, respectively.

From the above set of experiments, that the basic findings are as follows: (i) A price cut for a particular class of hotels tends to cause a demand drop for all the hotels from the lower-level class(es); (ii) The closest substitutes for 4-star hotels are 5-star hotels; the closest substitutes for 3-star hotels are 4-star and 2-star hotels; the closest substitutes for 2-star hotels are 1-star hotels.

\subsection{Estimation Results from Model Extensions}

As discussed in sections 4.3 and 4.4., we also empirically estimated the two extended models.

\section{(i) With additional text features}

The estimation results for the extended model with additional text features are shown in Table 4 . We see that the qualitative nature of our main results remains the same. In addition, we see that the three features that have a positive and statistically significant impact on demand are "food quality," "hotel staff" and "parking facilities." In contrast, "bedroom quality" had a negative impact on demand. While this negative sign is surprising, this can happen if consumers use bedroom quality as a cue for price, especially given that quality in our data is a proxy for the number of beds and size of the room (full, queen, king, etc). This is possible because sometimes prices are obfuscated on the main results page and are only available just before checkout. However, this is only one possible explanation.

\section{(ii) With interaction effects}

The additional interaction effects enable us to understand better how the distribution of consumers' heterogeneous preferences is influenced by the distribution of consumers' demographic information. More specifically, we estimated four sets of interaction effects:

1) Interaction between Income and Price;

2) Interaction between Travel Category and Price;

3) Interaction between Unobserved Consumer Characteristics and Hotel Characteristics.

4) Interaction between Travel Category and Hotel Characteristics (e.g., location, service, brand, etc.);

Due to the space limitation in this paper, we will only focus on the discussions of 2) and 4). The corresponding results for these two sets of interaction effects are provided in Table 5b, Table 5c, and Table 5 d. ${ }^{21}$ The estimated mean coefficients are shown in Table 5a.

\footnotetext{
${ }^{21}$ The results for 1) and 3) are available from the authors upon request.
} 
First, we notice that consumers' heterogeneous tastes towards price can indeed be explained by their various travel purposes. For example, from Table 5a, we know that the mean price coefficient is -0.121 . Thus, from Table 5b, we can infer that if a consumer is on a business trip, her price coefficient will increase 0.027 above the mean, which yields an adjusted price coefficient of -0.094 . On the contrary, if a consumer is on a family trip or a romance trip, her adjusted price coefficient is -0.133 or -0.126 , respectively. Among all different types of travelers, we found that tourists (i.e., travelers on a large group tour) tend to be the most price-sensitive with an adjusted price coefficient of -0.139 , whereas business travelers are the least price-sensitive. This consumer heterogeneity in price sensitivity can be further interpreted by the marginal effects of price change on hotel demand. For instance, we find that a $20 \%$ increase in hotel price will lead to a $1.58 \%$ demand drop from business travelers, compared to a $2.22 \%$ drop from family travelers, a $2.11 \%$ demand drop from romance travelers, and a $2.32 \%$ demand drop from tourists.

Furthermore, we find that consumer heterogeneity towards different hotel location and service characteristics is also associated with travel purpose. For instance, we notice that business travelers have the highest marginal valuation for "highway" and "public transportation." In other words, hotels with easy access to interstate highway or public transportations will attract business travelers the most. More specifically, this can be quantitatively interpreted by the marginal effects on hotel demand. From Table 5a, we see that the mean coefficients for "highway" and "transportation" are 0.066 and 0.158 , respectively. According to the estimated interaction effects in Table $5 \mathrm{c}$, we can infer that for business travelers the presence of "highway" and "transportation" weigh significantly higher than the mean coefficients, with an increase of 0.101 and 0.134 for each. Correspondingly, the presence of interstate highway near a hotel will increase hotel demand from business travelers by $17.43 \%$, compared to a $6.89 \%$ demand increase on average, and a $4.07 \%$ demand increase from romance travelers (which is less than $1 / 4$ of that from business travelers). Similarly, the presence of public transportation near a hotel will increase hotel demand from business travelers by $33.03 \%$, compared to an $17.87 \%$ demand increase on average, and a $9.05 \%$ demand increase from family travelers (which is only about $1 / 4$ of that from business travelers). On the contrary, we find that romance travelers are more sensitive to "hotel class" and "beach" compared to other types of travelers. For example, the presence of beach near a hotel will increase hotel demand from romance travelers by $27.69 \%$, compared to a $17.81 \%$ demand increase on average, and a $12.97 \%$ demand increase from business travelers (which is less than 1/2 of that from romance travelers). Similarly, a 1-star improvement in hotel class will lead to an increase in hotel demand from romance travelers by $19.53 \%$, compared to a $6.06 \%$ demand increase on average, and a significantly lower demand increase from tourists at a rate of only $2.57 \%$.

\section{Utility-Based Hotel Ranking}


After we estimate the parameters, we can derive the utility gain that a consumer with a particular travel purpose receives from paying for a given hotel. Thereafter, we propose to design a new ranking tool for hotels based on the average utility gain from transactions in that hotel. As discussed in Section 4, to capture the consumer heterogeneity, we represent the utility from each hotel for each consumer as consisting of two parts: the mean and the standard deviation. The mean utility provides us with a good estimation of how much consumers can benefit from choosing this particular hotel, while the standard deviation of utility describes the variance of this benefit. In our case, we are interested in knowing what the excess utility is for consumers on an aggregate level from choosing a certain hotel. Therefore, we define the average utility gain from hotel $j$ with travel category type $k$ as the sum of its mean utility, defined in Eq. (2.1) - divided by the mean price coefficient - over all markets:

$$
\text { Utility } \text { Gain }_{j^{k}}=\sum_{t} \frac{1}{\bar{\alpha}} \bar{\mu}_{i j^{k}}
$$

\subsection{Ranking Hotels}

We thereby propose a new ranking approach for hotels based on the utility gain from each hotel for consumers on an aggregate level. If a hotel provides a comparably higher utility gain, then it would appear on the top of our ranking list. Since the mean price coefficient is consistent over all hotels, and our final goal is to relatively compare hotels and rank them based on the utility gain, we can simply ignore $\bar{\alpha}$, which gives us the following form:

$$
\text { Utility } \operatorname{Gain}_{j^{k}}=\sum_{t} \frac{1}{\bar{\alpha}} \bar{\mu}_{i j^{k} t} \sim \sum_{t} \bar{\mu}_{i j^{k} t}
$$

Therefore, after estimating the economic impact for each hotel characteristic, we propose to design a local hotel ranking function based on the average utility gain that consumers get from the transactions in a given hotel. Then, we rank all the hotels according to the utility gain they provide to the consumers in an descending order. This provides us with the best valuation on the hotel cost performance and provides customers with the best-valued hotels, consequently.

\subsection{User Study Based on Field Experiments}

To evaluate the quality of our ranking technique, we conducted an extensive user study toward which we designed and executed several field experiments using Amazon Mechanical Turk. We generated different rankings for the top-10 hotels in accordance with several existing baseline criteria deployed by travel search engines: Most booked, Price low to high, Price high to low, Hotel class, Hotel size (number of rooms), and Number of internal amenities. We also considered 4 other benchmark criteria based on usergenerated content: Customer rating from Tripadvisor.com, Customer rating from Travelocity.com, Mixed 
rating from Tripadvisor.com and Travelocity.com ${ }^{22}$, and Maximum online review count. Moreover, to examine the significance of the user-generated content and of the comprehensive model to the overall performance of the ranking scheme, we generated two more baselines using the same hybrid model but excluding all the UGC variables, and using the BLP model (as described in Sec 5.2). Finally, we also generated a "combined ranking" using combined criteria of "price" and "hotel class" to examine whether a ranking that attempts to introduce diversity artificially can compete with our utility-based one. We did this by interlacing the top-5 hotels with "the lowest price" and the top-5 hotels with "the highest number of stars." This resulted in a total of 13 different experiments for each of the six cities (Los Angeles, New Orleans, New York, Orlando, San Francisco, and Salt Lake City) resulting in a total of 78 experiments each having 200 participants and involved more than 15,600 user comparisons of different ranking lists. ${ }^{23}$

We computed the expected utility for each hotel from our parameter estimates, and ranked the hotels in each city according to their average utility gain. Then we generated different rankings for the top-10 hotels in a given city based on various existing benchmark systems used in travel search engines. Then we presented our model generated ranking together with an alternative ranking and asked users to compare each pair of rankings, i.e., our ranking paired with one of the existing benchmarks. To avoid any potential bias, we did not release any information to the users about the criteria for generating those rankings and randomized the orders of presentation of the rankings. The studies in our ranking evaluations were blind, pair-wise, tests, in which the two rankings were presented side by side, and the user had to pick one of them, without having any further information beyond the list of the hotels in each.

A large majority of customers preferred our ranking, when listed in a blind setting, side-by-side with the other competing baseline techniques ( $\mathrm{p}=0.05$, sign test). Moreover, our ranking based on the hybrid model with UGC variables was significantly preferred over the one without UGC variables, and over the one generated based on the BLP model. Table $\mathrm{C}$ in Appendix $\mathrm{C}$ shows how often users preferred our own ranking scheme when presented side-by-side with an alternative. Notice that in all 78 experiments, we observe a statistically significant difference for our ranking $(\mathrm{p}=0.05$, sign test) and that each test was conducted using 200 participants. The overall set of results (in none of the 78 experiments our ranking was deemed worse), is a strong indication that our ranking strategy is preferable to the existing baselines.

As part of this study, we also asked consumers why they chose a particular ranking. This was done to better understand how users interpret the utility-based ranking. The majority of users indicated that our utility-based ranking promoted the idea that price was not the main factor in rating the quality of hotels.

\footnotetext{
${ }^{22}$ Since some hotels have zero reviews, we considered a mixed approach for their ratings. More details are provided in Appendix C.

${ }^{23}$ We also tried interlacing rankings with different criteria, such as "the highest price" and the "lowest number of stars," or "the lowest price" and the "lowest number of stars," or "the highest price" and the "highest number of stars."The results are similar. This suggests that customers prefer a list of hotels that specialize in a variety of characteristics, rather than a variety of hotels that each specialize in only one characteristic.
} 
Instead, a good ranking recommendation is one that could satisfy customers' multidimensional preferences for hotels. Moreover, users strongly preferred the diversity of the retrieved results, given that the list consisted of a mix of hotels cutting across several price and quality ranges. In contrast, the other ranking approaches tended to list hotel of only one type (e.g., very expensive for "star ratings," or mainly 3-star hotels for "most booked"). Notice that even the ranking baseline with the combined criteria showed the similar trend. This further indicates that customers prefer a list of hotels that each specializes in a variety of characteristics, rather than a variety of hotels that each specializes in only a few characteristics.

Of course, diversity of results is well-known to be a factor of user satisfaction in web search (Agichtein 2006). While we could potentially try to imitate solutions from web search and introduce diversity in the results in an exogenous manner, we observe that the approach based on "consumer utility" theory introduces diversity naturally in the results. This result seems intuitive: if a specific segment of the market systematically appears to be underpriced, hence introducing a non-diverse set of results, then market forces would modify the prices for the whole segment accordingly. Thus, these results dovetail well with our empirical estimation, which suggests that our utility-based ranking model can capture consumers' true purchase motivations.

Moreover, our user study indicates that a star-rating system would not come close to achieving the same goal. Apparently one could interpret a subject's star-rating as a discrete approximation of her utility for a hotel, thus ranking based on star-rating ought to perform as well as ranking based on utility as the latter is just a money-metric transformation of the former. However, this is not true. The reason is that the matching of consumers to hotels in star rating systems is not random. A consumer only rates the hotel that she has already chosen before (i.e., the one that maximizes her perceived utility gain). Consequently, the average star rating for each hotel need not reflect the population average utility but rather the satisfaction of consumers with their own choices. Thus, rankings based on average star ratings need not reflect a ranking based on average utility.

\section{Conclusions and Implications}

In this paper, we estimate the economic value of different hotel characteristics, especially the locationbased and service-based characteristics, given the associated local infrastructure. We propose a random coefficient hybrid structural model, taking into consideration the two sources of consumer heterogeneity introduced by the different travel occasions and different hotel characteristics. Combining this econometric model with user-generated content data, using techniques from text mining, image classification, social geo-tagging, human annotations and geo-mapping tools, we examine a unique dataset consisting of actual transactions for hotels located in the US and infer the economic impact of various hotel characteristics. We then incorporate them into a new hotel ranking system based on the derived average utility gain. By doing 
so, we can provide customers with the "best-value" hotels early on, hence, improving the quality of local searches for such hotels.

On a broader note, the objective of this paper was to illustrate how user-generated content (UGC) on the Internet can be mined and incorporated into a demand estimation model. Our inter-disciplinary approach can provide insights for using text mining and image classification techniques in economics and marketing research. Simultaneously, such research can also highlight the value of using an economic context to computer scientists to estimate both the intensity and the polarity of the UGC, especially in reviews and blogs. Towards this, we empirically estimated the economic value of different hotel characteristics, including both service based and location-based characteristics, from multiple sources of UGC.

Our research enables us to not only quantify the economic impact of hotel characteristics, but also, by reversing the logic of this analysis, enables us to identify the characteristics that most influence demand for a particular hotel. After inferring the economic significance of each characteristic, we incorporate them in a model of expected utility gain estimation. The end goal is to generate a ranking system that recommends hotels providing the best value for money on an average. The key idea is that hotels (or products in general) that provide consumers with a higher surplus should be ranked higher in response to consumer queries. We conducted blind tests using real users, recruited through AMT to examine how well our ranking system performs in comparison with existing alternatives. We find that our ranking performs significantly better than several baseline-ranking systems that are being currently used.

Such research can provide us with critical insights into how humans make choice when exposed to multiple ranked lists of choices on the same computer screen. Furthermore, by examining product search through the "economic lens" of utilities, we leverage and integrate theories of relevance from information retrieval and micro-economic theory. Our inter-disciplinary approach has the potential improve the quality of results displayed by any product search engine on the Internet and improve the quality of product choices that consumers perform through the Internet.

Our work has several limitations some of which can serve as fruitful areas for future research. One can further break down the textual content of user-generated reviews in order to extract multiple service amenity related dimensions of every single hotel and examine the economic impact of each amenity. This can be done by conducting auto topic extraction techniques from text mining, combining with sentimental analysis to evaluate the subjectivity level of each interesting topic. This will enable us to better recover customers' multi-dimensional heterogeneous tastes towards different product characteristics. In order to better understand the antecedents of consumer's decisions, future work can look not only at transaction data but also into their browsing history and learning behavior. Furthermore, by incorporating more individual level demographics and context information from the time of purchase, one can extend our techniques to infer utilities at a more personalized level. This will enable one to improve the evaluation process by comparing our recommendations with the results from the traditional collaborative filtering or content- 
based algorithms. Our model also has limited structure with regard to competition, which does not allow us to study the impact of entry-exit decisions of hotels in different regions. In our model, the travel categorylevel shock is independently and identically distributed across consumers and travel categories. However, there could also be correlations in the travel category shocks wherein a consumer combines multiple purposes in one trip occasion. ${ }^{24}$ While this our model does not capture this, it is a promising area for future work.

\footnotetext{
${ }^{24}$ We thank an anonymous reviewer for pointing this out.
} 


\section{References}

- Agichtein, E., Brill, E., Dumais, S., Ragno, R., 2006. Learning User Interaction Models for Predicting Web Search Result Preferences. Proceedings of the 29th annual international ACM SIGIR conference on Research and development in information retrieval pp 3-10.

- $\quad$ Ansari, A., C. Mela. 2003. E-customization. Journal of Marketing Research, 40(2) 131--145.

- $\quad$ Ansari, A., S. Essegaier, R. Kohli. 2000. Internet Recommendation Systems, Journal of Marketing Research, 37, pp. 363-375.

- Archak, N., A. Ghose and P.G. Ipeirotis. 2008. Deriving The Pricing Power Of Product Features By Mining Consumer Reviews, Working Paper, SSRN.

- Arnaud, D. B., J. Liechty, E. Huizingh, G. Lilien. 2008. Offering Online Recommendations with Minimum Customer Input Through Conjoint-Based Decision Aids. Marketing Science, 27(3), pp. 443-460.

- Athey, S., G. Imbens. 2007. Discrete Choice Models with Multiple Unobserved Choice Characteristics. International Economic Review, 48(4), pp. 1159-1192.

- Berndt, E. 1996. The Practice of Econometrics: Classic and Contemporary, Addison-Wesley Publishing Company, Reading, MA.

- Berry, S. 1994. Estimating Discrete Choice Models of Product Differentiation. RAND Journal of Economics (25). Pp. 242-262.

- Berry, S., J. Levinsohn, A. Pakes. 1995. Automobile Prices in Market Equilibrium. Econometrica (63). Pp. 841-890.

- Berry, S., O. Linton, A. Pakes. 2004. Limit Theorems for Estimating the Parameters of Differentiated Product Demand Systems. Review of Economic Studies (71). Pp. 613-654.

- Berry, S. and A. Pakes. 2007. The Pure Characteristics Demand Model. International Economic Review (48). Pp. 1193-1225.

- Bodapati, A. 2008. Recommender Systems With Purchase Data. Journal of Marketing Research, 45 (1), 77--93.

- $\quad$ Chevalier, J., D. Mayzlin. 2006. The Effect Of Word Of Mouth On Sales: Online Book Reviews. J. Marketing Res. 43(3) 345-354.

- Chintagunta 2001. Research Note Endogeneity and Heterogeneity in a Probit Demand Model: Estimation Using Aggregate Data. Marketing Science, 20(4), 442-456.

- Chintagunta, P., J.P. Dubé, K.Y. Goh. 2005. Beyond the Endogeneity Bias: The Effect of Unmeasured Brand Characteristics on Household-Level Brand Choice Models. Management Science Vol. 51, No. 5, May 2005, pp. 832-84.

- Chung, T.S., R. Rust, M. Wedel. 2009. My Mobile Music: An Adaptive Personalization System For Digital Audio Players, Marketing Science, 28 (1), 52--68.

- Das, S., M. Chen. 2007. Yahoo! For Amazon: Sentiment Extraction From Small Talk on the Web. Management Science 53(9) 1375-1388.

- Dellarocas, C., N. Awad, M. Zhang. 2007. Exploring The Value of Online Product Reviews In Forecasting Sales: The Case Of Motion Pictures. J. Interactive Marketing 21(4) 23-45.

- Duan, W., B. Gu, A. B. Whinston. 2008. Do Online Reviews Matter? An Empirical Investigation of Panel Data. Decision Support Systems 45(4) 1007-1016.

- Dube, J.P., J. Fox, L. Su 2009. Improving the Numerical Performance of BLP Static and Dynamic Discrete Choice Random Coefficients Demand Estimation, Working Paper, University of Chicago. 
- $\quad$ Eliashberg, J., S. K. Hui, Z. J. Zhang. 2007. From Story Line To Box Office: A New Approach For Green-Lighting Movie Scripts. Management Sci. 53(6) 881-893.

- Fader, P. S., B. G.S. Hardie. 1996. Modeling Consumer Choice Among SKUs. Journal of Marketing Research, 33 (November), pp. 442-452.

- Fellbaum, C. 1998. Wordnet: An Electronic Lexical Database. MIT Press.

- $\quad$ Forman, C., A. Ghose, B. Wiesenfeld. 2008. Examining The Relationship Between Reviews And Sales: The Role Of Reviewer Identity Disclosure In Electronic Markets. Inform. Systems Res. 19(3) 291313.

- Franklin, S., M. Wulder. 2002. Remote Sensing Methods In Medium Spatial Resolution Satellite Data Land Cover Classification Of Large Areas, Progress in Physical Geography (26), pp. 173-205.

- Fukuda, S., H. Hirosawa. 2001. Support Vector Machine Classification Of Land Cover: Application To Polarimetric SAR Data, in Proceedings of the IEEE International Geoscience \& Remote Sensing Symposium, pp. 187-189.

- Garbers, J., M. Niemann, M. Mochol. 2006. A Personalized Hotel Selection Engine, in Proceedings of the third European Semantic Web Conference, Budva, Montenegro, June.

- Ghose, A. 2009. Internet Exchanges For Used Goods: An Empirical Analysis of Trade Patterns And Adverse Selection. MIS Quarterly 33(1) 1-30.

- Ghose, A., P.G. Ipeirotis. 2010. Estimating The Helpfulness And Economic Impact Of Product Reviews: Mining Text And Reviewer Characteristics, Forthcoming, IEEE Transactions On Knowledge And Data Engineering.

- Ghose, A., P.G. Ipeirotis, A. Sundararajan. 2006. The Dimensions of Reputation in Electronic Markets. Working Paper, New York University, NY.

- Godes, D., D. Mayzlin. 2004. Using Online Conversations To Study Word of Mouth Communication. Marketing Science. 23(4) 545-560.

- Hausman, J., G. Leonard, D. Zona. 1994. Competitive Analysis With Differentiated Products. Annales d'Economie Et De Statistique. Vol. 34, Pp. 159-180.

- $\quad \mathrm{Hu}$, M., B. Liu. 2004. Mining And Summarizing Customer Reviews. Proceedings Of The Tenth ACM SIGKDD International Conference On Knowledge Discovery And Data Mining (KDD-2004). 168177.

- Hu, N., P.A. Pavlou, J. Zhang. 2006. Can Online Reviews Reveal A Product's True Quality? Empirical Findings And Analytical Modeling Of Online Word-Of-Mouth Communication. Proceedings Of The Seventh ACM Conference On Electronic Commerce, Pp. 324-330.

- Kelley, C. T. 2003. Solving Nonlinear Equations with Newton's Method. SIAM, Philadelphia, PA.

- Knittel, C. R., K. Metaxoglou. 2008. Estimation of Random Coefficient Demand Models: Challenges, Difficulties and Warnings. Working Paper, U.C. Davis.

- Lancaster, K. 1966. A New Approach To Consumer Theory. Journal Of Political Economy (74), Pp. 132-157.

- $\quad$ Lancaster, K. 1971. Consumer Demand: A New Approach. Columbia University Press, NY.

- Lee, T., E. Bradlow. 2007. Automatic Construction of Conjoint Attributes And Levels From Online Customer Reviews. University Of Pennsylvania, The Wharton School Working Paper

- Li, X., L. Hitt. 2008. Self-Selection and Information Role of Online Product Reviews. Information Systems Research 19(4).

- Liu 2006.Word-Of-Mouth For Movies: Its Dynamics And Impact On Box Office Revenue, Journal Of Marketing, 70 (3), 74-89 
- $\quad$ Liu, B., M. Hu, J. Cheng. 2005. Opinion Observer: Analyzing And Comparing Opinions On The Web. Proceedings Of The 14th International World Wide Web Conference (WWW 2005). 342-351. Press.

Manning, C., H. Schutze. 1999. Foundations of Statistical Natural Language Processing. The MIT

- $\quad$ Moe, W. 2009. How Much Does A Good Product Rating Help A Bad Product? Modeling The Role Of Product Quality In The Relationship Between Online Consumer Ratings And Sales, Working Paper, University Of Maryland College Park.

- Nair, H., J.P. Dube, P. Chintagunta 2005. Accounting for Primary and Secondary Demand Effects with Aggregate Data. Marketing Science. 24(3), 444-460.

- Nevo, A., 2000. A Practitioner's Guide to Estimation of Random Coefficients Logit Models of Demand, Journal of Economics \& Management Strategy, 9(4), 513-548.

- Nevo, A., 2001. Measuring Market Power in the Ready-to-Eat Cereal Industry, Econometrica, Vol. 69, No. 2. pp. 307-342.

- Nevo, A., A. Rosen. 2008. Identification with Imperfect Instruments, Working Paper, SSRN.

- $\quad$ Nocedal, J., S. J. Wright (2006): Numerical Optimization. Springer, New York, NY.

- Pang, B., L. Lee. 2004. A Sentimental Education: Sentiment Analysis Using Subjectivity Summarization Based On Minimum Cuts, in Proceedings of the 42nd Annual Meeting of the Association for Computational Linguistics, pp. 271-278.

- $\quad$ Popescu, A., O. Etzioni. 2005. Extracting product features and opinions from reviews. Proceedings of Human Language Technology Conference and Conference on Empirical Methods in Natural Language Processing (HLT/EMNLP 2005). 339-346.

- Rosen, S. 1974. Hedonic Prices And Implicit Markets: Product Differentiation In Pure Competition, Journal of Political Economy (82:1), pp. 34-55.

- $\quad$ Rust, R.T., T.S. Chung. 2006. Marketing Models of Service And Relationships. Marketing Science. 25 (6) 560-580.

- Scaffidi, C., K. Bierhoff, E. Chang, M.Felker, H. Ng, C. Jin. 2007. Red Opal: Product-Feature Scoring From Reviews. Proceedings of the 8th ACM conference on Electronic commerce (EC'07). 182191.

- Shy, Oz. 1996. Industrial Organization: Theory and Applications. The MIT Press.

- Song, M. 2007. Measuring consumer welfare in the CPU market: an application of the purecharacteristics demand model. RAND Journal of Economics, 38(2), 429-446.

- Song, M. 2010. A Hybrid Discrete Choice Model of Differentiated Product Demand with an Application to Personal Computers. Simon School Working Paper No. FR 08-09. Available at SSRN: http://ssrn.com/abstract=1315271.

- $\quad$ Steckel, J., W. Vanhonacker. 1993. Cross-Validating Regression Models in Marketing Research. Marketing Science, 12(4) pp. 415-427.

- Villas-Boas, J. Miguel, Russell S. Winer. 1999. Endogeneity in Brand Choice Models. Management Science 45(10) 1324-1338.

- White S. 2003. The 2003 national assessment of adult literacy (NAAL). Technical Report NCES 2003495rev, Center for Education Statistics (NCES), Institute of Education Sciences, U.S. Department of Education, March 2003.

- Ying, Y., F. Feinberg, M. Wedel. 2006. Leveraging Missing Ratings To Improve Online Recommendation Systems. Journal of Marketing Research, 43(3) 355-365. 
Table 1: Summary of Different Methods for Extracting Hotel Characteristics

\begin{tabular}{|c|c|c|c|}
\hline Category & \multicolumn{2}{|c|}{ Hotel Characteristics } & Methods \\
\hline Transaction Data & \multicolumn{2}{|c|}{$\begin{array}{l}\text { Transaction Price (per room per night) } \\
\text { Number of Rooms sold (per night) }\end{array}$} & Travelocity \\
\hline Service-based & \multicolumn{2}{|c|}{$\begin{array}{l}\text { Hotel Class } \\
\text { Hotel Amenities }\end{array}$} & Tripadvisor \\
\hline \multirow{4}{*}{ Review-based } & \multicolumn{2}{|c|}{$\begin{array}{l}\text { Number of Customer Reviews } \\
\text { Overall Reviewer Rating } \\
\text { Disclosure of Reviewer Identity Information }\end{array}$} & Travelocity and Tripadvisor \\
\hline & Subjectivity & $\begin{array}{l}\text { Mean Probability } \\
\text { Std. Dev. Of Probability }\end{array}$ & \multirow{3}{*}{ Text Analysis } \\
\hline & Readability & $\begin{array}{l}\text { Number of Characters } \\
\text { Number of Syllables } \\
\text { Number of Spelling Errors } \\
\text { Average Length of Sentence } \\
\text { SMOG Index }\end{array}$ & \\
\hline & (Additional) & $\begin{array}{l}\text { Breakfast } \\
\text { Hotel Staff } \\
\text { Bathroom } \\
\text { Bedroom } \\
\text { Parking } \\
\end{array}$ & \\
\hline \multirow{5}{*}{ Location-based } & \multicolumn{2}{|c|}{$\begin{array}{l}\text { Near the Beach } \\
\text { Near Downtown }\end{array}$} & $\begin{array}{l}\text { Image Classification, } \\
\text { Tags from Geonames.org and } \\
\text { Social Annotations from } \\
\text { Amazon Mechanical Turk }\end{array}$ \\
\hline & \multicolumn{2}{|c|}{$\begin{array}{r}\text { External Amenities (Number of restaurants/ } \\
\text { Shopping destinations) }\end{array}$} & $\begin{array}{l}\text { Microsoft Virtual Earth Geo- } \\
\text { Mapping Search SDK }\end{array}$ \\
\hline & \multicolumn{2}{|c|}{ Near Public Transportation } & Tags from Geonames.org \\
\hline & \multicolumn{2}{|c|}{$\begin{array}{l}\text { Near the Interstate Highway } \\
\text { Near the Lake/River }\end{array}$} & $\begin{array}{l}\text { Social Annotations from } \\
\text { Amazon Mechanical Turk }\end{array}$ \\
\hline & \multicolumn{2}{|c|}{ City Annual Crime Rate } & FBI online statistics \\
\hline
\end{tabular}


Table 2: Definitions and Summary Statistics of Variables

\begin{tabular}{|c|c|c|c|c|c|}
\hline Variable & Definition & Mean & Std. Dev. & Min & Max \\
\hline PRICE & Transaction price per room per night & 126.59 & 79.47 & 12 & 978 \\
\hline CHARACTERS & Average number of characters & 766.54 & 167.13 & 121 & 2187 \\
\hline COMPLEXITY & Average sentence length & 16.41 & 3.95 & 2 & 44. \\
\hline SYLLABLES & Average number of syllables & 245.48 & 53.77 & 37 & 700 \\
\hline SMOG & SMOG index & 9.91 & .63 & 3 & 19.80 \\
\hline SPELLERR & Average number of spelling errors & 1.10 & .37 & 0 & 3.33 \\
\hline$S U B$ & Subjectivity - mean & .99 & .03 & .05 & 1 \\
\hline SUBDEV & Subjectivity - standard deviation & .02 & .02 & 0 & .25 \\
\hline$I D$ & Disclosure of reviewer identity & .77 & .14 & 0 & 1 \\
\hline CLASS & Hotel class & 3.02 & .93 & 1 & 5 \\
\hline CRIME & City annual crime rate & 195.09 & 123.11 & 3 & 1310 \\
\hline AMENITYCNT & Total number of hotel amenities & 16.38 & 3.21 & 2 & 23 \\
\hline EXTAMENITY & $\begin{array}{l}\text { Number of external amenities within } 1 \\
\text { mile, i.e., restaurants or shops }\end{array}$ & 4.95 & 7.37 & 0 & 27 \\
\hline$B E A C H$ & Beachfront within 0.6 miles & .24 & .43 & 0 & 1 \\
\hline$L A K E$ & Lake or river within 0.6 miles & .23 & .42 & 0 & 1 \\
\hline TRANS & Public transportation within 0.6 miles & .11 & .31 & 0 & 1 \\
\hline HIGHWAY & Highway exits within 0.6 miles & .68 & .47 & 0 & 1 \\
\hline DOWNTOWN & Downtown area within 0.6 miles & .69 & .46 & 0 & 1 \\
\hline TA_REVIEWCNT & Total number of reviews (TripAdvisor) & 127.81 & 164.22 & 0 & 999 \\
\hline$T A \_R E V I E W C N T^{\wedge} 2$ & Square of TA_REVIEWCNT & 28573.16 & 70943.83 & 0 & 998001 \\
\hline$T A \_R A T I N G$ & Overall reviewer rating (TripAdvisor) & 3.49 & .59 & 1 & 5 \\
\hline$T L \_R E V I E W C N T$ & Total number of reviews (Travelocity) & 25.26 & 29.77 & 0 & 202 \\
\hline$T L \_R E V I E W C N T^{\wedge} 2$ & Square of $T L \_R E V I E W C N T$ & 731.40 & 1794.81 & 0 & 40804 \\
\hline$T L \_R A T I N G$ & Overall reviewer rating (Travelocity) & 3.87 & .74 & 1 & 5 \\
\hline
\end{tabular}


Table 3: Main Estimation Results

\begin{tabular}{|c|c|c|c|c|c|c|c|c|c|}
\hline Variable & $\begin{array}{c}\text { Coef. } \\
(\text { Std. Err) }\end{array}$ & $\begin{array}{c}\text { Coef. } \\
(\text { Std. Err })^{\mathrm{II}}\end{array}$ & $\begin{array}{c}\text { Coef. } \\
(\text { Std. Err) }\end{array}$ & $\begin{array}{c}\text { Coef. } \\
\left(^{\text {(Std. Err })^{\mathrm{A} 1}}\right. \\
\end{array}$ & $\begin{array}{c}\text { Coef. } \\
\left(_{\text {(Std. Err) }}\right)^{\mathbf{A} 2} \\
\end{array}$ & $\begin{array}{c}\text { Coef. } \\
(\text { Std. Err })^{\mathbf{A 3}}\end{array}$ & $\begin{array}{c}\text { Coef. } \\
\left(^{\text {Std. Err })^{\mathrm{A4}}}\right.\end{array}$ & $\begin{array}{c}\text { Coef. } \\
(\text { Std. Err) }\end{array}$ & $\begin{array}{c}\text { Coef. } \\
\left(_{\text {(Std. Err) }}{ }^{\mathrm{N}}\right. \\
\end{array}$ \\
\hline \multicolumn{10}{|c|}{ Means } \\
\hline Price $^{(L)}$ & $-.122^{* * *}(.002)$ & $-.121^{* * *}(.003)$ & $-.119^{* * *}(.002)$ & $-.128^{* * *}(.006)$ & $-.132^{* * * *}(.005)$ & $-.131^{* * * * *}(.005)$ & $-.124^{* * * *}(.003)$ & $-.122^{* * *}(.003)$ & $-.121^{* * *}(.002)$ \\
\hline CHARACTERS $S^{(L)}$ & $.009^{* * *}(.002)$ & $.009^{* * * *}(.002)$ & $.009^{* * * *}(.002)$ & $.009^{* * *}(.003)$ & $.008^{* * *}(.003)$ & $.008^{* * *}(.003)$ & $.008^{* * * *}(.002)$ & $.009^{* * * *}(.002)$ & $.009^{* * * *}(.002)$ \\
\hline COMPLEXITY & $-.010^{* * *}(.002)$ & $-.010^{* * *}(.003)$ & $-.010^{* * *}(.003)$ & $-.015^{* * *}(.002)$ & $-.012^{* * * *}(.003)$ & $-.012^{* * *}(.002)$ & $-.010^{* * * *}(.002)$ & $-.011^{* * *}(.003)$ & $-.011^{* * *}(.003)$ \\
\hline$S Y L L A B L E S^{(L)}$ & $-.040^{* * * *}(.006)$ & $-.041^{* * *}(.006)$ & $-.042^{* * *}(.006)$ & $-.039^{* * *}(.006)$ & $-.046^{* * *}(.006)$ & $-.045^{* * *}(.006)$ & $-.041^{* * *}(.006)$ & $-.044^{* * *}(.006)$ & $-.043^{* * * *}(.006)$ \\
\hline$S M O G$ & $.076^{* * *}(.025)$ & $.075^{* *}(.025)$ & $.077^{* *}(.026)$ & $.071^{* * *}(.025)$ & $.079^{* * *}(.026)$ & $.088^{* * * *}(.025)$ & $.075^{* *}(.026)$ & $.072^{* *}(.025)$ & $.073^{* *}(.024)$ \\
\hline SPELLERR ${ }^{(L)}$ & $-.128^{* * *}(.003)$ & $-.128^{* * * *}(.004)$ & $-.128^{* * * *}(.004)$ & $-.125^{* * *}(.003)$ & $-.130^{* * *}(.003)$ & $-.146^{* * *}(.005)$ & $-.131^{* * *}(.004)$ & $-.127^{* * *}(.003)$ & $-.129^{* * *}(.003)$ \\
\hline$S U B$ & $-.146^{* * *}(.007)$ & $-.149^{* * *}(.007)$ & $-.152^{* * *}(.008)$ & $-.147^{* * *}(.007)$ & $-.152^{* * *}(.007)$ & $-.160^{* * *}(.008)$ & $-.147^{* * *}(.007)$ & $-.147^{* * *}(.007)$ & $-.145^{* * *}(.007)$ \\
\hline SUBDEV & $-.420^{* * *}(.008)$ & $-.422^{* * *}(.008)$ & $-.425^{* * *}(.009)$ & $-.417^{* * *}(.008)$ & $-.432^{* * *}(.010)$ & $-.437^{* * *}(.012)$ & $-.426^{* * *}(.008)$ & $-.422^{* * *}(.007)$ & $-.424^{* * *}(.008)$ \\
\hline$I D$ & $.054^{*} \quad(.023)$ & $.055^{*} \quad(.024)$ & $.056^{*} \quad(.027)$ & $.049^{*} \quad(.024)$ & $.056^{*} \quad(.022)$ & $.059^{*} \quad(.024)$ & $.055^{*} \quad(.026)$ & $.052^{*} \quad(.026)$ & $.050^{*} \quad(.026)$ \\
\hline CLASS & $.032^{* * * *}(.009)$ & $.034^{* * *}(.009)$ & $.037^{* * *}(.009)$ & $.036^{* * *}(.007)$ & $.041^{* * * *}(.009)$ & $.050^{* * *}(.008)$ & $.033^{* * * *}(.008)$ & $.032^{* * * *}(.009)$ & $.034^{* * * *}(.008)$ \\
\hline$C R I M E^{(L)}$ & $-.023^{*} \quad(.016)$ & $-.025^{*} \quad(.015)$ & $-.029^{*} \quad(.015)$ & $-.024^{*} \quad(.015)$ & $-.025^{*} \quad(.016)$ & $-.028^{*} \quad(.016)$ & $-.022^{*} \quad(.015)$ & $-.024^{*} \quad(.015)$ & $-.023^{*} \quad(.015)$ \\
\hline$A M E N I T Y C N T^{(L)}$ & $.005^{*} \quad(.002)$ & $.004^{*} \quad(.002)$ & $.005^{*} \quad(.002)$ & $.005^{*} \quad(.002)$ & $.006^{*} \quad(.003)$ & $.010^{* *}(.004)$ & $.006^{* * *}(.001)$ & $.006^{*} \quad(.003)$ & $.005^{*} \quad(.002)$ \\
\hline EXTAMENITY $Y^{(L)}$ & $.007^{* * *}(.001)$ & $.008^{* * *}(.002)$ & $.008^{* * *}(.002)$ & $.008^{* * * *}(.002)$ & $.011^{* * *}(.002)$ & $.009^{* * * *}(.002)$ & $.007^{* * *}(.001)$ & $.006^{* * * *}(.001)$ & $.007^{* * * *}(.002)$ \\
\hline$B E A C H$ & $.153^{* * * *}(.003)$ & $.156^{* * * *}(.003)$ & $.158^{* * *}(.003)$ & $.152^{* * * *}(.002)$ & $.158^{* * *}(.003)$ & $.159^{* * *}(.003)$ & $.152^{* * * *}(.003)$ & $-.021^{* * *}(.003)$ & $.154^{* * * *}(.012)$ \\
\hline TRANS & $.156^{* * *}(.002)$ & $.159^{* * * *}(.003)$ & $.167^{* * * *}(.005)$ & $.152^{* * * *}(.003)$ & $.155^{* * *}(.003)$ & $.162^{* * * *}(.004)$ & $.157^{* * *}(.003)$ & $.157^{* * * *}(.003)$ & $.151^{* * * *}(.020)$ \\
\hline$H I G H W A Y$ & $.068^{*} \quad(.028)$ & $.070^{* *} \quad(.025)$ & $.064^{*} \quad(.027)$ & $.071^{* *}(.025)$ & $.072^{* *}(.025)$ & $.074^{* * *}(.025)$ & $.068^{*} \quad(.027)$ & $.069^{*} \quad(.028)$ & $.077^{* * * *}(.018)$ \\
\hline DOWNTOWN & $.040^{* * * *}(.003)$ & $.045^{* * *}(.003)$ & $.045^{* * * *}(.003)$ & $.041^{* * *}(.002)$ & $.043^{* * * *}(.003)$ & $.044^{* * *}(.003)$ & $.043^{* * * *}(.001)$ & $.041^{* * * *}(.002)$ & $.042^{* * *}(.011)$ \\
\hline TA_RATING & $.039^{* * *}(.017)$ & $.040^{* *}(.018)$ & $.035^{*} \quad(.018)$ & $.040^{* *}(.017)$ & $.044^{* *}(.017)$ & $.046^{* *}(.017)$ & $.042^{* *}(.018)$ & $.040^{* * *}(.017)$ & $.040^{* *}(.014)$ \\
\hline$T L \_R A T I N G$ & $.035^{* * * *}(.009)$ & $.036^{* * * *}(.009)$ & $.035^{* * * *}(.008)$ & $.038^{* * * *}(.009)$ & $.040^{* * * *}(.009)$ & $.041^{* * * *}(.008)$ & $.035^{* * * *}(.008)$ & $.035^{* * * *}(.009)$ & $.038^{* * * *}(.008)$ \\
\hline$T A \_R E V I E W C N T^{(L)}$ & $.184^{* * *}(.045)$ & $.186^{* * *}(.046)$ & $.182^{* * *}(.045)$ & $.175^{* * * *}(.046)$ & $.189^{* * * *}(.046)$ & $.178^{* * * *}(.046)$ & $.185^{* * *}(.045)$ & $.182^{* * *}(.045)$ & $.181^{* * *}(.034)$ \\
\hline$T A \_R E V I E W C N T^{\wedge} 2^{(L)}$ & $-.052^{* * *}(.006)$ & $-.053^{* * *}(.006)$ & $-.052^{* * * *}(.006)$ & $-.064^{* * * *}(.007)$ & $-.062^{* * *}(.006)$ & $-.064^{* * *}(.006)$ & $-.055^{* * *}(.005)$ & $-.052^{* * * *}(.005)$ & $-.060^{* * *}(.002)$ \\
\hline$T L \_R E V I E W C N T^{(L)}$ & $.013^{* * * *}(.002)$ & $.012^{* * * *}(.002)$ & $.012^{* * * *}(.002)$ & $.012^{* * *}(.003)$ & $.015^{* * * *}(.003)$ & $.014^{* * *}(.003)$ & $.014^{* * *}(.003)$ & $.014^{* * * *}(.002)$ & $.010^{* * *}(.001)$ \\
\hline$T L \_R E V I E W C N T^{\wedge} 2^{(L)}$ & $-.021^{* * *}(.006)$ & $-.023^{* * *}(.005)$ & $-.024^{* * * *}(.005)$ & $-.021^{* * * *}(.005)$ & $-.024^{* * *}(.005)$ & $-.024^{* * *}(.005)$ & $-.022^{* * *}(.005)$ & $-.024^{* * *}(.005)$ & $-.021^{* * *}(.002)$ \\
\hline Constant & $.016^{* * *}(.002)$ & $.022^{* * * *}(.002)$ & $.027^{* * *}(.002)$ & $.024^{* * * *}(.003)$ & $.011^{* * * *}(.002)$ & $.019^{* * * *}(.003)$ & $.015^{* * * *}(.001)$ & $.021^{* * * *}(.004)$ & $.059^{* *}(.020)$ \\
\hline
\end{tabular}

${ }^{25}$ We use dummy variables to control for 9 major hotel brands: Accor, Best Western, Cendant, Choice, Hilton, Hyatt, Intercontinental, Marriott, and Starwood. The detailed information on these brands is provided in Table 5 . 


\begin{tabular}{|c|c|c|c|c|c|c|c|c|c|c|}
\hline \multicolumn{2}{|c|}{ Instruments } & Price & Price & Price & $\begin{array}{l}\text { Lag Price with } \\
\text { Google Trend }\end{array}$ & $\begin{array}{r}\text { Cost - Employee } \\
\text { Wage }\end{array}$ & $\begin{array}{r}\text { Cost }- \text { Region } \\
\text { Dummies }\end{array}$ & $\begin{array}{r}\text { BLP Style } \\
\text { Instruments }\end{array}$ & Price & Price \\
\hline \multicolumn{2}{|c|}{$\begin{array}{c}\text { Distribution of } \\
\text { idiosyncratic error } \\
\text { term }\end{array}$} & $\begin{array}{r}\text { Type I } \\
\text { Extreme Value }\end{array}$ & $\begin{array}{r}\text { Type I } \\
\text { Extreme Value }\end{array}$ & $\begin{array}{r}\text { Type I } \\
\text { Extreme Value }\end{array}$ & $\begin{array}{r}\text { Type I } \\
\text { Extreme Value }\end{array}$ & $\begin{array}{r}\text { Type I } \\
\text { Extreme Value }\end{array}$ & $\begin{array}{r}\text { Type I } \\
\text { Extreme Value }\end{array}$ & $\begin{array}{r}\text { Type I } \\
\text { Extreme Value }\end{array}$ & $\begin{array}{r}\text { Type I } \\
\text { Extreme Value }\end{array}$ & $\begin{array}{r}\text { Normal } \\
\text { Distribution }\end{array}$ \\
\hline \multicolumn{2}{|c|}{ HIGH TEMP } & $\begin{array}{l}---- \\
\end{array}$ & $\begin{array}{ll}--- \\
--1\end{array}$ & $\begin{array}{ll}--- \\
-1\end{array}$ & $\begin{array}{ll}--- \\
---\end{array}$ & $\begin{array}{ll}--- \\
---\end{array}$ & $\begin{array}{ll}--- \\
---\end{array}$ & $\begin{array}{c}--- \\
-1\end{array}$ & $\begin{array}{ll}.087 \quad(.071) \\
\end{array}$ & $-\cdots$ \\
\hline \multicolumn{2}{|c|}{$H I G H T E M P * L A K E$} & ---- & ---- & ---- & ---- & ---- & --- & --- & $.017^{* * * *}(.002)$ & --- \\
\hline \multicolumn{2}{|c|}{$H I G H T E M P * B E A C H$} & ---- & --- & --- & --- & --- & ---- & ---- & $.178^{* * * *}(.044)$ & --- \\
\hline \multicolumn{11}{|c|}{ Standard Deviations } \\
\hline & & $1.2 \mathrm{e}-6$ & $1.7 \mathrm{e}-6$ & $1.6 \mathrm{e}-6$ & $1.9 \mathrm{e}-6$ & $2.0 \mathrm{e}-6$ & $2.0 \mathrm{e}-6$ & $1.8 \mathrm{e}-6$ & $2.2 \mathrm{e}-6$ & $1.5 \mathrm{e}-6$ \\
\hline & & .0012 & .0011 & .0011 & .0012 & .0015 & .0015 & .0011 & .0013 & .0012 \\
\hline \multicolumn{2}{|c|}{ GMM Obj Value } & $4.587 \mathrm{e}-18$ & $9.014 \mathrm{e}-18$ & $4.395 \mathrm{e}-17$ & $2.901 \mathrm{e}-17$ & $4.262 \mathrm{e}-17$ & $2.520 \mathrm{e}-17$ & $5.663 \mathrm{e}-18$ & $2.787 \mathrm{e}-17$ & $9.916 \mathrm{e}-18$ \\
\hline$* * *$ & \multicolumn{10}{|c|}{ Significant at a $0.1 \%$ level. } \\
\hline$* *$ & \multicolumn{10}{|c|}{ Significant at a $1 \%$ level. } \\
\hline$*$ & \multicolumn{10}{|c|}{ Significant at a $5 \%$ level. } \\
\hline$\dagger$ & \multicolumn{10}{|c|}{ Significant at a $10 \%$ level. } \\
\hline I & \multicolumn{10}{|c|}{ Based on the main dataset (at least 1 review from either TA or TL). } \\
\hline III & \multicolumn{10}{|c|}{ Based on the main dataset with review count $>=10$. } \\
\hline A1 & \multicolumn{10}{|c|}{ Alternative Instruments 1 - Lag Price with Google Trend } \\
\hline A2 & \multicolumn{10}{|c|}{ Alternative Instruments 2 - Employee Wage } \\
\hline A3 & \multicolumn{10}{|c|}{ Alternative Instruments 3 - Region Dummy variables (Northeast, South, Midwest, Southwest, West) } \\
\hline A4 & \multicolumn{10}{|c|}{ Alternative Instruments 4 - BLP Style Instruments (Average characteristics of the same-star hotels in other markets) } \\
\hline $\mathrm{T}$ & \multicolumn{10}{|c|}{ Based on dataset I, considering interactions of temperatures with "lake/river" and with "beach." } \\
\hline $\mathrm{N}$ & \multicolumn{10}{|c|}{ Normal distribution of the idiosyncratic error term. } \\
\hline (L) & \multicolumn{10}{|c|}{ Logarithm of the variable. } \\
\hline
\end{tabular}




\section{Table 5: Extended Model (II) -With Additional Interaction Effects ${ }^{26}$}

5a) Mean coefficients from the extended model.

\begin{tabular}{|c|c|c|c|c|}
\hline \multicolumn{5}{|c|}{ Mean Coefficients } \\
\hline Price $^{(L)}$ & $-.121^{* * * *}$ & $(.002)$ & $B E A C H$ & $.155^{* * * *}(.004)$ \\
\hline CHARACTERS $S^{(L)}$ & $.009^{* * *}$ & $(.002)$ & $L A K E$ & $-.114^{* * *}(.023)$ \\
\hline COMPLEXITY & $-.011^{* * * *}$ & $(.002)$ & TRANS & $.158^{* * * *}(.003)$ \\
\hline$S Y L L A B L E S^{(L)}$ & $-.042^{* * *}$ & $(.007)$ & $H I G H W A Y$ & $.066^{*}(.030)$ \\
\hline$S M O G$ & $.078^{* *}$ & $(.027)$ & DOWNTOWN & $.042^{* * * *}(.002)$ \\
\hline SPELLERR ${ }^{(L)}$ & $-.125^{* * *}$ & $(.003)$ & $T A \_R A T I N G$ & $.034^{* *}(.014)$ \\
\hline$S U B$ & $-.142^{* * *}$ & $(.007)$ & $T L \_R A T I N G$ & $.030^{* *}(.011)$ \\
\hline$S U B D E V$ & $-.418^{* * *}$ & $(.012)$ & $T A \_R E V I E W C N T^{(L)}$ & $.182^{* * *}(.042)$ \\
\hline$I D$ & $.058^{*}$ & $(.029)$ & $T A \_R E V I E W C N T^{\wedge} 2^{(L)}$ & $-.051^{* * *}(.006)$ \\
\hline CLASS & $.040^{* * * *}$ & $(.009)$ & $T L \_R E V I E W C N T^{(L)}$ & $.015^{* * *}(.003)$ \\
\hline CRIME & $-.025^{*}$ & $(.017)$ & $T L \_R E V I E W C N T^{\wedge} 2^{(L)}$ & $-.019^{* *}(.007)$ \\
\hline$A M E N I T Y C N T^{(L)}$ & $.005^{* *}$ & $(.002)$ & Constant & $.020^{* *}(.012)$ \\
\hline EXTAMENITY ${ }^{(L)}$ & $.007^{* * * *}$ & $(.002)$ & & \\
\hline
\end{tabular}

5b) Interaction effects between Travel Purpose and Price.

\begin{tabular}{|c|c|}
\hline & $P R I C E^{(L)}$ \\
\hline FAMILY & $-.012^{* * *}(.002)$ \\
\hline BUSINESS & $.027^{* * *}(.003)$ \\
\hline$R O M A N C E$ & $-.005^{* *}(.002)$ \\
\hline TOURIST & $-.018^{* * * *}(.005)$ \\
\hline KIDS & $.014^{* *}(.007)$ \\
\hline SENIORS & $.088 \quad(.053)$ \\
\hline PETS & $(.033)$ \\
\hline DISABILITY & $-.013 \quad(.017)$ \\
\hline
\end{tabular}

${ }^{26}$ Note: $\quad * * * \mathrm{P}<=0.001, \quad * * \mathrm{P}<=0.01, \quad * \mathrm{P}<=0.05, \quad \dagger \mathrm{P}<=0.1$.

(L) Logarithm of the variable. 
5c) Interaction effects between Travel Purpose and Hotel Characteristics.

\begin{tabular}{|c|c|c|c|c|c|c|c|}
\hline & CLASS & HIGHWAY & DOWNTOWN & $\begin{array}{c}\text { TRANSPORT } \\
\text { ATIONS }\end{array}$ & BEACH & LAKE & $\begin{array}{c}\text { EXTERNAL } \\
\text { AMENITIES }^{(L)}\end{array}$ \\
\hline FAMILY & $.037^{* * * *}(.009)$ & $-.025^{* * * *}(.008)$ & $.119^{* * * *}(.007)$ & $-.078^{*} \quad(.035)$ & $-.045 \quad(.037)$ & $-.184 \quad(.177)$ & $\begin{array}{ll}.057 & (.102)\end{array}$ \\
\hline BUSINESS & $.014^{*} \quad(.008)$ & $.101^{* *}(.035)$ & $-.012 \quad(.016)$ & $.134^{* * *}(.018)$ & $-.042^{* *}(.017)$ & $.016 \quad(.075)$ & $.005^{* *}(.002)$ \\
\hline ROMANCE & $.089^{* * * *}(.011)$ & $-.027^{* *}(.012)$ & $-.017 \quad(.023)$ & $-.034^{* *}(.012)$ & $.086^{* * * *}(.012)$ & $-.027^{*}(.014)$ & $.008^{* *}(.003)$ \\
\hline TOURIST & $-.023^{* * *}(.006)$ & $.026^{* * *}(.005)$ & $-.077^{* *}(.024)$ & $\begin{array}{ll}-.067 \quad(.098)\end{array}$ & $-.110^{* * *}(.033)$ & $-.133(.211)$ & $-.002 \quad(.003)$ \\
\hline$K I D S$ & $.025^{*} \quad(.015)$ & $.055^{* * *}(.011)$ & $.092^{* * * *}(.025)$ & $.010 \quad(.012)$ & $.102^{* * * *}(.021)$ & $-.025 \quad(.024)$ & $.006^{* * * *}(.001)$ \\
\hline SENIORS & $.041 \quad(.038)$ & $.087 \quad(.141)$ & $-.016 \quad(.039)$ & $.109 \quad(.213)$ & $\begin{array}{ll}.018 \quad(.035)\end{array}$ & $-.064 \quad(.154)$ & $\begin{array}{ll}-.002 \quad(.007)\end{array}$ \\
\hline PETS & $-.097 \quad(.118)$ & $.204 \quad(.215)$ & $.128 \quad(.113)$ & $-.076^{* * *}(.026)$ & $\begin{array}{ll}-.041 \quad(.014)\end{array}$ & $.022 \quad(.042)$ & $.020 \quad(.045)$ \\
\hline DISABILITY & $-.069 \quad(.078)$ & $-.018 \quad(.079)$ & $-.052 \quad(.100)$ & $-.055 \quad(.123)$ & $\begin{array}{ll}.065 \quad(.081) \\
\end{array}$ & $-.275 \quad(250)$ & $\begin{array}{ll}-.017 \quad(.014) \\
\end{array}$ \\
\hline
\end{tabular}

5d) Interaction effects between Travel Purpose and Hotel brands:

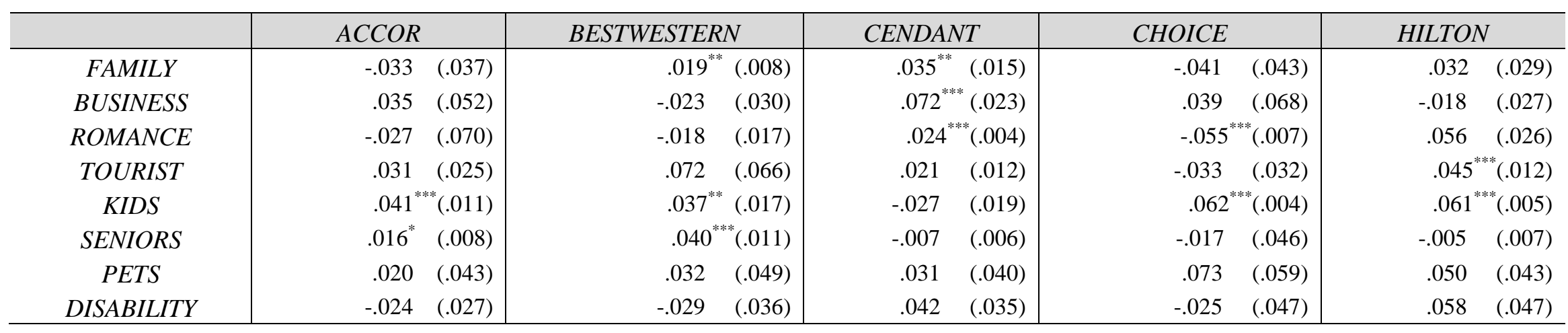




\begin{tabular}{|c|c|c|c|c|c|}
\hline & HYATT & INTERCONTINENTAL & MARRIOTT & STARWOOD & OTHERS \\
\hline FAMILY & $.042^{* * *}(.011)$ & $.014 \quad(.013)$ & $.019 \quad(.022)$ & $.025^{* *}(.012)$ & $-.033^{* *}(.015)$ \\
\hline BUSINESS & $-.007^{* * *}(.002)$ & $.015^{* * *}(.003)$ & $-.004 \quad(.008)$ & $.023 \quad(.020)$ & $.021 \quad(.017)$ \\
\hline ROMANCE & $-.010 \quad(.012)$ & $\begin{array}{ll}-.001 \quad(.007) & \end{array}$ & $-.077^{* * * *}(.018)$ & $-.027^{* *}(.013)$ & $.038^{* * * *}(.011)$ \\
\hline KIDS & $.025^{* *}(.010)$ & $.024 \quad(.016)$ & $.035^{* *}(.013)$ & $.058^{* *}(.025)$ & $-.038^{* * * *}(.004)$ \\
\hline SENIORS & $-.009 \quad(.010)$ & $-.007 \quad(.011)$ & $.023 \quad(.047)$ & $.011 \quad(.024)$ & $.004 \quad(.017)$ \\
\hline
\end{tabular}

Note: All hotel brands considered in our study represent major hotel groups that may contain several sub-brands as listed below.

Accor: $\quad$ Sofitel, Pullman, MGallery, Novotel, Mercure, and Suitehotel.

Best Western: Best Western.

Cendant: $\quad$ Howard Johnson, Days Inn, Ramada, Travelodge, Knights Inn, Wingate Inn, Super 8, and Amerihost Inn.

Choice: $\quad$ Comfort Inn, Comfort Suites, Cambria Suites, Ascend Collection, Quality Inn, Clarion, Sleep Inn, Econo Loddge, Rodeway Inn, Suburban, and MainStay Suites.

Hilton: $\quad$ Conrad, Hilton, Waldorf Astoria, Double Tree, Embassy Suites, Hilton Garden Inn, Hampton, Homewood suites, and Hilton Grand Vacations.

Hyatt: $\quad$ Hyatt Regency, Grand Hyatt, Park Hyatt, Hyatt Vacation Club, Hyatt Resort, Hyatt Summerfield Suites, Hyatt Place, and ANDAZ.

InterContinental: InterContinental, Crowne Plaza, Holiday Inn, Holiday Inn Express, Candlewood Suites, Hotel INDIGO and Staybridge Suites.

Marriott: $\quad$ Marriott, JW Marriott, Renaissance, EDITION, Autograph Collection, Courtyard, Residence Inn, Fairfield Inn, TownePlace Suite, SpringHill Suites, Ritz-Carlton, Marriott ExecuStay, Marriott Vacation Club, Marriott Executive Apartments, and Grand Residences.

Starwood: Sheraton, St.Regis, The Luxury Collection, Westin, Four Points, W Hotel, Aloft, Element, and Le Meridien. 


\section{Appendix A}

Table A1: Robustness Test (I) -Using Alternative Sample Splits

\begin{tabular}{|c|c|c|c|}
\hline Variable & Coef. (Std. Err) $)^{\text {IV }}$ & Coef. (Std. Err) ${ }^{\mathrm{V}}$ & Coef. (Std. Err) ${ }^{\mathrm{VI}}$ \\
\hline \multicolumn{4}{|c|}{ Means } \\
\hline Price $^{(L)}$ & $-.124^{* * *}(.002)$ & $-.123^{* * *}(.003)$ & $-.122^{* * *}(.003)$ \\
\hline CHARACTERS $S^{(L)}$ & $.010^{* * * *}(.002)$ & $.010^{* * * *}(.002)$ & $.009^{* * * *}(.002)$ \\
\hline COMPLEXITY & $-.010^{* * *}(.002)$ & $-.011^{* * *}(.002)$ & $-.010^{* * *}(.002)$ \\
\hline$S Y L L A B L E S^{(L)}$ & $-.041^{* * *}(.006)$ & $-.044^{* * *}(.006)$ & $-.039^{* * *}(.006)$ \\
\hline$S M O G$ & $.076^{* *}(.025)$ & $.071^{* *}(.027)$ & $.070^{* *}(.027)$ \\
\hline SPELLERR $R^{(L)}$ & $-.127^{* * *}(.004)$ & $-.121^{* * *}(.005)$ & $-.128^{* * *}(.004)$ \\
\hline$S U B$ & $-.150^{* * * *}(.006)$ & $-.156^{* * *}(.007)$ & $-.149^{* * *}(.007)$ \\
\hline SUBDEV & $-.415^{* * *}(.009)$ & $-.409^{* * *}(.007)$ & $-.412^{* * *}(.009)$ \\
\hline$I D$ & $.055^{*} \quad(.025)$ & $.058^{\dagger} \quad(.035)$ & $.059^{\dagger} \quad(.035)$ \\
\hline CLASS & $.033^{* * *}(.010)$ & $.041^{* * * *}(.010)$ & $.039^{* * *}(.010)$ \\
\hline$C R I M E^{(L)}$ & $-.024^{*} \quad(.017)$ & $-.023^{*} \quad(.014)$ & $-.024^{*} \quad(.014)$ \\
\hline$A M E N I T Y C N T^{(L)}$ & $.006^{*} \quad(.003)$ & $.004 \quad(.003)$ & $.006^{*} \quad(.003)$ \\
\hline EXTAMENITY $Y^{(L)}$ & $.008^{* * *}(.002)$ & $.007^{* *}(.003)$ & $.006^{* * *}(.002)$ \\
\hline$B E A C H$ & $.155^{* * *}(.004)$ & $.150^{* * *}(.003)$ & $.152^{* * *}(.004)$ \\
\hline$L A K E$ & $-.104^{* * * *}(.029)$ & $-.110^{* * *}(.026)$ & $-.117^{* * *}(.028)$ \\
\hline TRANS & $.158^{* * *}(.006)$ & $.161^{* * *}(.005)$ & $.161^{* * *}(.005)$ \\
\hline$H I G H W A Y$ & $.069^{*} \quad(.032)$ & $.067^{*}(.033)$ & $.066^{*}(.034)$ \\
\hline DOWNTOWN & $.038^{* * *}(.005)$ & $.042^{* * *}(.005)$ & $.040^{* * *}(.005)$ \\
\hline$T A \_R A T I N G$ & $.042^{*} \quad(.022)$ & $.044^{*} \quad(.028)$ & $.044^{*} \quad(.028)$ \\
\hline$T L \_R A T I N G$ & $.034^{* * *}(.011)$ & $.031^{*} \quad(.017)$ & $.032^{*} \quad(.016)$ \\
\hline$T A \_R E V I E W C N T^{(L)}$ & $.181^{* * * *}(.045)$ & $.182^{* * * *}(.041)$ & $.182^{* * * *}(.044)$ \\
\hline$T A \_R E V I E W C N T^{\wedge} 2^{(L)}$ & $-.047^{* * *}(.006)$ & $-.046^{* * *}(.006)$ & $-.047^{* * *}(.006)$ \\
\hline$T L \_R E V I E W C N T^{(L)}$ & $.013^{* * *}(.003)$ & $.014^{* * * *}(.004)$ & $.014^{* * *}(.004)$ \\
\hline$T L \_R E V I E W C N T^{\wedge} 2^{(L)}$ & $-.023^{* * *}(.005)$ & $-.022^{* * *}(.005)$ & $-.025^{* * *}(.005)$ \\
\hline Constant & $.025^{*} \quad(.018)$ & $.037^{* *}(.018)$ & $.031^{*} \quad(.017)$ \\
\hline Brand Control & Yes & Yes & Yes \\
\hline \multicolumn{4}{|c|}{ Standard Deviations } \\
\hline$\alpha_{I}$ & $1.9 \mathrm{e}-6$ & $1.8 \mathrm{e}-6$ & $2.1 \mathrm{e}-6$ \\
\hline$\beta_{v}$ & .0015 & .0014 & .0010 \\
\hline GMM Obj Value & $9.341 \mathrm{e}-18$ & $8.822 \mathrm{e}-18$ & $1.001 \mathrm{e}-17$ \\
\hline$* * * \mathrm{P}<=0.001$ & $* * \mathrm{P}<=0.01$ & $* \mathrm{P}<=0.05$ & $\dagger \mathrm{P}<=0.1$ \\
\hline $\begin{array}{l}\text { IV. Filtered dataset (>= } \\
\text { VI. Filtered dataset (at le } \\
\text { (L) Logarithm of the var }\end{array}$ & $\begin{array}{l}\text { view from TA). } \\
1 \text { review from both } \mathrm{T} \\
\text { le. }\end{array}$ & $\begin{array}{l}\text { Filtered dataset (>= } \\
\text { TL). }\end{array}$ & iew from TL). \\
\hline
\end{tabular}


Table A2: Robustness Test (II) - Using BLP Model

\begin{tabular}{|c|c|c|c|c|c|c|c|}
\hline Variable & Coef. (Std. Err) ${ }^{I}$ & Coef. (Std. Err) ${ }^{\mathrm{II}}$ & Coef. (Std. Err) $)^{\mathrm{III}}$ & Coef. (Std. Err) $)^{\mathrm{IV}}$ & Coef. (Std. Err) ${ }^{\mathrm{V}}$ & Coef. (Std. Err) $)^{\mathrm{VI}}$ & Coef. (Std. Err) ${ }^{R}$ \\
\hline \multicolumn{8}{|c|}{ Means } \\
\hline Price $^{(L)}$ & $-.230^{* * * *}(.044)$ & $-.237^{* * *}(.044)$ & $-.231^{* * *}(.044)$ & $-.240^{* * *}(.049)$ & $-.242^{* * *}(.049)$ & $-.251^{* * *}(.052)$ & $-.229^{* * *}(.063)$ \\
\hline CHARACTERS $S^{(L)}$ & $.029^{* * *}(.002)$ & $.029^{* * *}(.003)$ & $.029^{* * *}(.003)$ & $.034^{* * *}(.004)$ & $.035^{* * *}(.005)$ & $.039^{* * *}(.006)$ & $.032^{* * *}(.003)$ \\
\hline COMPLEXITY & $-.009^{*} \quad(.005)$ & $-.009^{*}(.005)$ & $-.010^{*}(.005)$ & $-.014^{* *}(.005)$ & $-.017^{* *}(.006)$ & $-.021^{* * *}(.006)$ & $-.012^{* * *}(.004)$ \\
\hline$S Y L L A B L E S^{(L)}$ & $-.126^{* * * *}(.017)$ & $-.127^{* * *}(.017)$ & $-.127^{* * * *}(.018)$ & $-.126^{* * *}(.020)$ & $-.126^{* * *}(.021)$ & $-.129^{* * *}(.023)$ & $-.126^{* * *}(.022)$ \\
\hline$S M O G$ & $.139^{\dagger} \quad(.098)$ & $.140^{\dagger} \quad(.099)$ & $.139^{\dagger} \quad(.100)$ & $.138^{\dagger} \quad(.103)$ & $.137^{\dagger} \quad(.104)$ & $.141^{\dagger}(.105)$ & $.140^{\dagger} \quad(.101)$ \\
\hline$S P E L L E R R^{(L)}$ & $-.092^{*} \quad(.039)$ & $-.094^{*}(.039)$ & $-.093^{*} \quad(.039)$ & $-.101^{* *}(.040)$ & $-.104^{* *}(.038)$ & $-.112^{* *}(.040)$ & $-.098^{* *}(.037)$ \\
\hline$S U B$ & $-.236^{*} \quad(.107)$ & $-.242^{*} \quad(.107)$ & $-.240^{*}(.108)$ & $-.249^{*}(.113)$ & $-.274^{* *}(.114)$ & $-.271^{* *}(.114)$ & $-.240^{*} \quad(.110)$ \\
\hline SUBDEV & $-.521^{*} \quad(.261)$ & $-.523^{*} \quad(.261)$ & $-.524^{*}(.262)$ & $-.533^{*}(.265)$ & $-.536^{*} \quad(.263)$ & $-.542^{*}(.278)$ & $-.527^{*}(.266)$ \\
\hline$I D$ & $.145^{*} \quad(.090)$ & $.147^{*}(.090)$ & $.146^{*} \quad(.090)$ & $.152^{*}(.092)$ & $.155^{*}(.092)$ & $.168^{*}(.096)$ & $.150^{*} \quad(.091)$ \\
\hline CLASS & $.059^{* * *}(.012)$ & $.058^{* * * *}(.012)$ & $.058^{* * *}(.012)$ & $.064^{* * *}(.012)$ & $.066^{* * *}(.012)$ & $.071^{* * *}(.012)$ & $.059^{* * *}(.013)$ \\
\hline CRIME & $-.097^{*}(.052)$ & $-.099^{*} \quad(.053)$ & $-.096^{*}(.053)$ & $-.096^{*}(.053)$ & $-.101^{*}(.053)$ & $-.092^{\dagger} \quad(.058)$ & $-.099^{*}(.054)$ \\
\hline$A M E N I T Y C N T^{(L)}$ & $.032^{* * *}(.013)$ & $.033^{* *}(.013)$ & $.033^{* *}(.013)$ & $.035^{* *}(.013)$ & $.037^{* *}(.014)$ & $.043^{* *}(.016)$ & $.031^{* *}(.012)$ \\
\hline EXTAMENITY ${ }^{(L)}$ & $.049^{* * *}(.004)$ & $.056^{* * * *}(.004)$ & $.058^{* * * *}(.005)$ & $.058^{* * * *}(.006)$ & $.059^{* * * *}(.006)$ & $.065^{* * *}(.009)$ & $.053^{* * *}(.005)$ \\
\hline$B E A C H$ & $.397^{* * * *}(.092)$ & $.401^{* * * *}(.093)$ & $.404^{* * *}(.096)$ & $.416^{* * *}(.102)$ & $.418^{* * *}(.103)$ & $.422^{* * *}(.110)$ & $.402^{* * *}(.109)$ \\
\hline$L A K E$ & $-.158^{*} \quad(.087)$ & $-.154^{*}(.089)$ & $-.159^{*}(.091)$ & $-.163^{*}(.092)$ & $-.164^{*}(.093)$ & $-.177^{*} \quad(.095)$ & $-.162^{*}(.091)$ \\
\hline TRANS & $.422^{* * *}(.100)$ & $.425^{* * *}(.098)$ & $.434^{* * *}(.100)$ & $.432^{* * *}(.101)$ & $.433^{* * *}(.100)$ & $.453^{* * *}(.106)$ & $.425^{* * *}(.102)$ \\
\hline$H I G H W A Y$ & $.414^{* * *}(.090)$ & $.411^{* * *}(.090)$ & $.418^{* * *}(.092)$ & $.419^{* * *}(.092)$ & $.421^{* * *}(.092)$ & $.422^{* * *}(.093)$ & $.416^{* * *}(.093)$ \\
\hline DOWNTOWN & $.203^{* *}(.089)$ & $.205^{* *}(.092)$ & $.211^{* *}(.092)$ & $.214^{* *}(.093)$ & $.215^{* *}(.093)$ & $.212^{* *}(.092)$ & $.207^{* *}(.091)$ \\
\hline$T A \_R A T I N G$ & $.112^{* * *}(.023)$ & $.114^{* * *}(.023)$ & $.118^{* * *}(.026)$ & $.117^{* * *}(.026)$ & $.117^{* * *}(.026)$ & $.117^{* * *}(.026)$ & $.114^{* * * *}(.023)$ \\
\hline$T L \_R A T I N G$ & $.105^{* * * *}(.021)$ & $.108^{* * *}(.023)$ & $.106^{* * *}(.023)$ & $.106^{* * *}(.023)$ & $.107^{* * *}(.024)$ & $.108^{* * *}(.025)$ & $.108^{* * * *}(.022)$ \\
\hline$T A \_R E V I E W C N T^{(L)}$ & $.346^{\dagger} \quad(.239)$ & $.351^{\dagger}(.238)$ & $.362^{\dagger}(.239)$ & $.358^{\dagger} \quad(.238)$ & $.353^{\dagger}(.239)$ & $.361^{\dagger}(.241)$ & $.349^{\dagger} \quad(.240)$ \\
\hline$T A \_R E V I E W C N T^{\wedge} 2^{(L)}$ & $-.045^{* * * *}(.003)$ & $-.048^{* * *}(.003)$ & $-.043^{* * *}(.003)$ & $-.043^{* * *}(.004)$ & $-.048^{* * *}(.004)$ & $-.049^{* * *}(.004)$ & $-.045^{* * *}(.004)$ \\
\hline$T L \_R E V I E W C N T^{(L)}$ & $.093^{*}(.052)$ & $.099^{*}(.053)$ & $.107^{*}(.052)$ & $.109^{*}(.057)$ & $.111^{*}(.061)$ & $.120^{*} \quad(.064)$ & $.104^{*} \quad(.058)$ \\
\hline$T L \_R E V I E W C N T^{\wedge} 2^{(L)}$ & $-.035^{*}(.019)$ & $-.035^{*}(.018)$ & $-.035^{*}(.018)$ & $-.041^{*}(.016)$ & $-.040^{*}(.018)$ & $-.042^{*}(.016)$ & $-.036^{*}(.018)$ \\
\hline Constant & $.038 \quad(.128)$ & $.056 \quad(.287)$ & $.285^{* * *}(.079)$ & $.124 \quad(.344)$ & $.059^{* *}(.020)$ & $.068 \quad(.114)$ & $.007 \quad(.005)$ \\
\hline Brand Control & Yes & Yes & Yes & Yes & Yes & Yes & Yes \\
\hline
\end{tabular}




\begin{tabular}{|c|c|c|c|c|c|c|c|c|}
\hline & $\begin{array}{l}\text { Travel Category with } \\
\text { Homogeneous Coef. }{ }^{27}\end{array}$ & Yes & Yes & Yes & Yes & Yes & Yes & No \\
\hline & $\begin{array}{l}\text { Travel Category with } \\
\text { Random Coef. }\end{array}$ & No & No & No & No & No & No & Yes \\
\hline \multicolumn{9}{|c|}{ Standard Deviations } \\
\hline & $\alpha_{1}$ & $1.0 \mathrm{e}-6$ & $1.1 \mathrm{e}-6$ & $1.1 \mathrm{e}-6$ & $1.1 \mathrm{e}-6$ & $1.2 \mathrm{e}-6$ & $1.2 \mathrm{e}-6$ & $1.0 \mathrm{e}-6$ \\
\hline & $\beta_{v}$ & .0021 & .0018 & .0019 & .0015 & .0022 & .0019 & .0023 \\
\hline & GMM Obj Value & $7.821 \mathrm{e}-18$ & $7.365 \mathrm{e}-18$ & $8.026 \mathrm{e}-18$ & $3.111 \mathrm{e}-17$ & $3.013 \mathrm{e}-17$ & $5.524 \mathrm{e}-18$ & 7.966e-18 \\
\hline \multicolumn{9}{|c|}{ *** $\quad$ Significant at a $0.1 \%$ level. } \\
\hline$* *$ & \multicolumn{8}{|c|}{ Significant at a $1 \%$ level. } \\
\hline$*$ & \multicolumn{8}{|c|}{ Significant at a $5 \%$ level. } \\
\hline$\dagger$ & \multicolumn{8}{|c|}{ Significant at a $10 \%$ level. } \\
\hline I & \multicolumn{8}{|c|}{ Based on the main dataset (at least 1 review from either TA or TL). } \\
\hline II & \multicolumn{8}{|c|}{ Based on the main dataset with review count $>=5$. } \\
\hline III & \multicolumn{8}{|c|}{ Based on the main dataset with review count $>=10$. } \\
\hline IV & \multicolumn{8}{|c|}{ Based on the filtered dataset (at least 1 review from TA). } \\
\hline $\mathrm{V}$ & \multicolumn{8}{|c|}{ Based on the filtered dataset (at least 1 review from TL). } \\
\hline VI & \multicolumn{8}{|c|}{ Based on the filtered dataset (at least 1 review from both TA and TL). } \\
\hline $\mathrm{R}$ & \multicolumn{8}{|c|}{ Based on dataset I, with random coefficients on travel category dummies. } \\
\hline (L) & \multicolumn{8}{|c|}{ Logarithm of the variable. } \\
\hline
\end{tabular}

\footnotetext{
${ }^{27}$ We consider dummy variables with homogeneous coefficients to control for the 8 corresponding travel categories.

${ }^{28} \mathrm{We}$ consider dummy variables with random coefficients to control for the 8 corresponding travel categories.
} 


\section{Appendix B}

In-sample and Out-of-sample Model Comparison Results

Table B1: In-sample Basic Model Validation Results

\begin{tabular}{cccccc}
\hline & $\begin{array}{c}\text { Hybrid } \\
\text { Model }\end{array}$ & $\begin{array}{c}\text { BLP without } \\
\text { Random } \\
\text { Coef. on Travel } \\
\text { Categories }\end{array}$ & $\begin{array}{c}\text { BLP with } \\
\text { Random } \\
\text { Coef. on Travel } \\
\text { Categories }\end{array}$ & PCM & $\begin{array}{c}\text { Nested Logit } \\
\text { (Random Utility } \\
\text { Maximization) }\end{array}$ \\
\hline RMSE & 0.0433 & 0.0584 & 0.0523 & 0.0991 & 0.1158 \\
MSE & 0.0019 & 0.0034 & 0.0027 & 0.0098 & 0.0134 \\
MAD & 0.0160 & 0.0187 & 0.0180 & 0.0308 & 0.0379 \\
\hline
\end{tabular}

Table B2: In-sample Extended Model Validation Results

\begin{tabular}{ccc}
\hline & $\begin{array}{c}\text { Hybrid Model With } \\
\text { Interaction Effects }\end{array}$ & $\begin{array}{c}\text { BLP With } \\
\text { Interaction Effects }\end{array}$ \\
\hline RMSE & 0.0388 & 0.0467 \\
MSE & 0.0015 & 0.0022 \\
MAD & 0.0126 & 0.0170 \\
\hline \multicolumn{2}{c}{ 10-fold Cross-Validation } & Estimation Sample Size: $\mathbf{5 6 6 9}$ \\
\hline
\end{tabular}

Table B3: In-sample Model Validation Results by Excluding Certain Features

\begin{tabular}{cccc}
\hline & $\begin{array}{c}\text { Hybrid Model } \\
\text { Without UGC } \\
\text { Variables }\end{array}$ & $\begin{array}{c}\text { Hybrid Model } \\
\text { Without Location } \\
\text { Variables }\end{array}$ & $\begin{array}{c}\text { Hybrid Model } \\
\text { Without Service } \\
\text { Variables }\end{array}$ \\
\hline RMSE & 0.0769 & 0.1217 & 0.1135 \\
MSE & 0.0059 & 0.0148 & 0.0129 \\
MAD & 0.0336 & 0.0374 & 0.0367 \\
\hline 10-fold Cross-Validation & Estimation Sample Size: $\mathbf{5 6 6 9}$ \\
\hline
\end{tabular}


Table B4: Out-of-sample Basic Model Validation Results

\begin{tabular}{|c|c|c|c|c|c|}
\hline & $\begin{array}{c}\text { Hybrid } \\
\text { Model }\end{array}$ & $\begin{array}{c}\text { BLP without } \\
\text { Random } \\
\text { Coef. on Travel } \\
\text { Categories }\end{array}$ & $\begin{array}{c}\text { BLP with } \\
\text { Random } \\
\text { Coef. on Travel } \\
\text { Categories }\end{array}$ & PCM & $\begin{array}{c}\text { Nested Logit } \\
\text { (Random Utility } \\
\text { Maximization) }\end{array}$ \\
\hline RMSE & 0.0920 & 0.1028 & 0.1005 & 0.1959 & 0.2399 \\
\hline MSE & 0.0085 & 0.0106 & 0.0101 & 0.0384 & 0.0576 \\
\hline MAD & 0.0293 & 0.0373 & 0.0411 & 0.0556 & 0.1311 \\
\hline 10-fold & \multicolumn{5}{|c|}{ Estimation Sample Size: 5669} \\
\hline Cross-Validation & \multicolumn{5}{|c|}{ Holdout Sample Size: } \\
\hline
\end{tabular}

Table B5: Out-of-sample Extended Model Validation Results

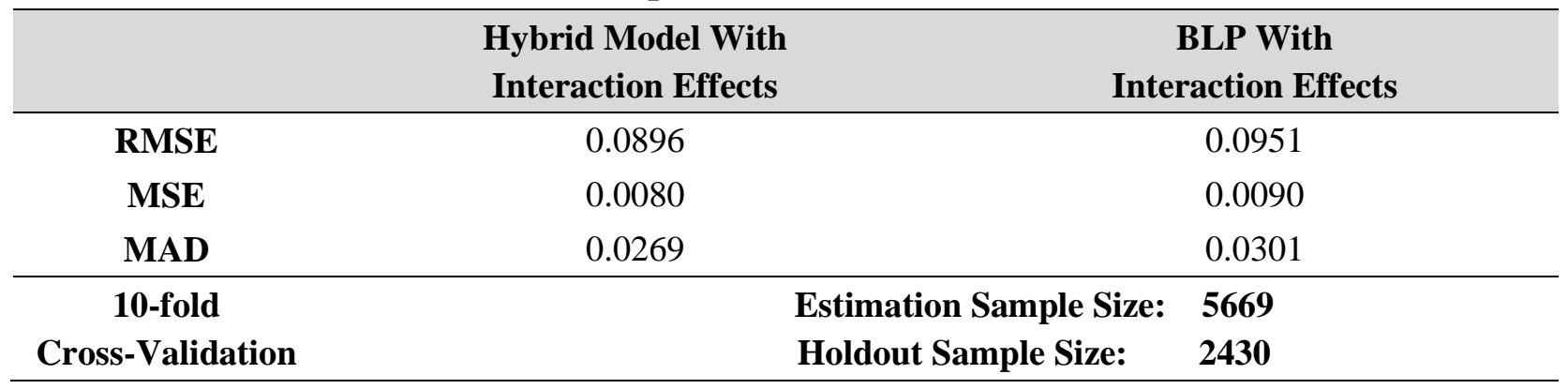

Table B6: Out-of-sample Model Validation Results by Excluding Certain Features

\begin{tabular}{cccc}
\hline & $\begin{array}{c}\text { Hybrid Model } \\
\text { Without UGC } \\
\text { Variables }\end{array}$ & $\begin{array}{c}\text { Hybrid Model } \\
\text { Without Location } \\
\text { Variables }\end{array}$ & $\begin{array}{c}\text { Hybrid Model } \\
\text { Without Service } \\
\text { Variables }\end{array}$ \\
\hline RMSE & 0.1433 & 0.2047 & 0.1934 \\
MSE & 0.0205 & 0.0419 & 0.0374 \\
MAD & 0.0977 & 0.1293 & 0.1166 \\
\hline 10-fold & & Estimation Sample Size: & $\mathbf{5 6 6 9}$ \\
Cross-Validation & & Holdout Sample Size: & $\mathbf{2 4 3 0}$ \\
\hline
\end{tabular}




\section{Appendix C}

Table C: Ranking User Study Results

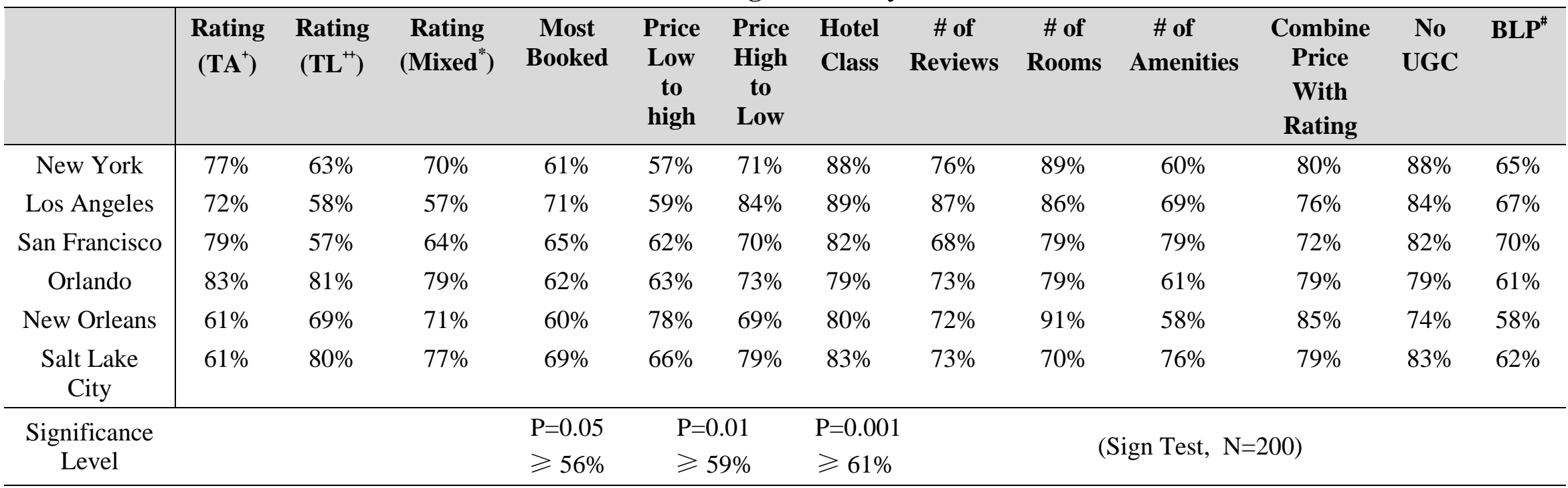

$+\quad$ TripAdvisor.com

++ Travelocity.com

* $\quad$ Mixed Rating Strategy: (i) Average of Tripadvisor rating and Travelocity rating when both are available;

(ii) Equal to one of the two ratings if the other one is missing;

(iii) Zero when both ratings are missing.

\# BLP with homogeneous coefficients on travel category dummies. 


\section{Appendix D Market Share Calculation}

Our model is motivated by the model in Song (2010). A rational consumer with a marginal utility of income $\alpha_{i}$ chooses travel category $k$ over other travel categories if and only if the best hotel (the one that provides the highest utility) within this travel category exceeds the best hotel within any other travel category:

$$
\max _{j^{k} \in H_{k}}\left(\delta_{j^{k}}+X_{j^{k} k_{t}} \beta_{v} v_{i}-\alpha_{I} I_{i} P_{j^{k_{t}}}\right)+\varepsilon_{i t}^{k}>\max _{j^{r} \in H_{r}}\left(\delta_{j^{r} t}+X_{j^{r} t} \beta_{v} v_{i}-\alpha_{I} I_{i} P_{j^{r_{t}}}\right)+\varepsilon_{i t}^{r}, \quad \forall r \neq k .
$$

Thus, similar to Song (2010), by assuming $\varepsilon$ has a type I extreme value distribution ${ }^{29}$, we can calculate the market share for a travel category type $k$ as the probability of this category being chosen:

$$
s_{k}=\iint \frac{\exp \left(\max _{j^{k} \in H_{k}}\left(\delta_{j^{k}}+X_{j^{k} k_{t}} \beta_{v} v_{i}-\alpha_{I} I_{i} P_{j^{k}}\right)\right)}{1+\sum_{r=1}^{K} \exp \left(\max _{j^{r} \in H_{r}}\left(\delta_{j^{r} t}+X_{j^{r} r_{t}} \beta_{v} v_{i}-\alpha_{I} I_{i} P_{j^{r_{t}}}\right)\right)} f(I) g(v) d I d v .
$$

Furthermore, within travel category $k$ consumer $i$ chooses hotel $j^{k}$ if and only if its utility exceeds the utility from any of the other hotels within the same travel category:

$$
\delta_{j^{k} t}+X_{j^{k}} \beta_{v} v_{i}-\alpha_{I} I_{i} P_{j^{k} t}>\delta_{h^{k} t}+X_{h^{k} t} \beta_{v} v_{i}-\alpha_{I} I_{i} P_{h^{k}}, \quad \forall h^{k} \in H_{k} \text { and } h^{k} \neq j^{k},
$$

where $H_{k}$ represents the subset of hotels with travel category type $k$. This can be transformed to

$$
\left(\delta_{j^{k} t}-\delta_{h^{k_{t}}}\right)+\left(X_{j^{k_{t}}}-X_{h^{k} k_{t}}\right) \beta_{v} v_{i}>\alpha_{I} I_{i}\left(P_{j^{k} t}-P_{h^{k_{t}}}\right) .
$$

Similar to Berry and Pakes (2007), we rank the hotels within each travel category in the order of ascending price. Therefore, conditioning on $v_{i}$, a consumer with income type $I_{i}$ will choose hotel $j^{k}$ if and only if

$$
\begin{aligned}
& I_{i}<\min _{j^{k}>h^{k}} \frac{\left(\delta_{j^{k} t}-\delta_{h^{k}}\right)+\left(X_{j^{k_{t}}}-X_{h^{k_{t}}}\right) \beta_{v} v_{i}}{\alpha_{I}\left(P_{j^{k} t}-P_{h^{k_{t}}}\right)} \equiv \bar{\Delta}(\bullet \theta, v), \\
& \text { and } I_{i}>\max _{j^{k}<h^{k}} \frac{\left(\delta_{j^{k_{t}}}-\delta_{h^{k}}\right)+\left(X_{j^{k_{t}}}-X_{h^{k_{t}}}\right) \beta_{v} v_{i}}{\alpha_{I}\left(P_{j^{k}}-P_{h^{k_{t}}}\right)} \equiv \underline{\Delta}(\bullet \mid \theta, v) .
\end{aligned}
$$

Let $F(\bullet)$ denote the cdf of $I_{i}$, and $G(\bullet)$ denote the cdf of $v_{i}$. Similar to Song (2010), the market share of hotel $j$ within travel category type $k$ can be calculated as

$$
s_{(j \mid \text { category }=k)}=\int\left[F\left(\bar{\Delta}_{j}^{k}(\bullet \mid \theta, v)\right)-F\left(\underline{\Delta}_{j} k(\bullet \mid \theta, v)\right)\right] 1\left[\bar{\Delta}_{j}^{k}(\bullet \mid \theta, v)>\underline{\Delta}_{j} k(\bullet \mid \theta, v)\right] d G(v),
$$

where $1[\cdot]$ is an indicator for the condition, and $\theta$ is a vector containing $\alpha_{I}$ and $\beta_{v}$. Note here, in

\footnotetext{
${ }^{29}$ As a robustness check, we tested different assumptions for $\varepsilon$ (e.g., using a normal distribution), consistent with Chintagunta (2001). Our results showed high consistency with the previous estimates (i.e., based on the Type I extreme value distribution), similar to findings of Chintagunta (2001). The results are given in the last column of Table 3.
} 
order to compute the income upper bound $\bar{\Delta}(\bullet \mid \theta, v)$ and lower bound $\underline{\Delta}(\bullet \mid \theta, v)$, we need the value of $\theta$. Given the set of values for $\theta$, this integration is typically not analytically solvable. For this reason, we use a Monte Carlo simulation to approximate it. Since $v_{i}$ follows the standard normal distribution $v_{i} \sim N(0,1)$, we can obtain an unbiased estimator of this integral by taking $n s_{v}$ random draws of $v_{i}$ : $s_{(j \mid c a t e g o r y=k)}\left(\delta, p, X ; \theta, F, G_{n s}\right) \equiv \frac{1}{n s_{v}} \sum_{i}^{n s}\left[F\left(\bar{\Delta}_{j}^{k}\left(\bullet, \theta, v_{i}\right)\right)-F\left(\underline{\Delta}_{j}^{k}\left(\cdot, \theta, v_{i}\right)\right)\right] 1\left[\bar{\Delta}_{j}^{k}\left(\bullet, \theta, v_{i}\right)>\underline{\Delta}_{j}^{k}\left(\bullet, \theta, v_{i}\right)\right]$

We can further derive the market share, which is the probability that a hotel $j$ within category type $k$ is chosen by consumer type $\left(I_{i}, v_{i}\right)$, to be the following

$$
s_{j}{ }_{j}=\iint_{I_{i}, v_{i} \in C_{j} k} \frac{\exp \left(\delta_{j^{k} t}+X_{j^{k} t} \beta_{v} v_{i}-\alpha_{I} I_{i} P_{j^{k}}\right)}{1+\sum_{r=1}^{K} \exp \left(\max _{j^{r} \in H_{r}}\left(\delta_{j^{r_{t}}}+X_{j^{r}{ }_{t}} \beta_{v} v_{i}-\alpha_{I} I_{i} P_{j^{r} r_{t}}\right)\right)} f(I) g(v) d I d v
$$

where $I_{i}, v_{i} \in C_{j^{k}}$ indicates consumers who choose hotel $j$ in travel category $k$. Note that there is no max function in the numerator. As suggested by Song (2010), this market share function can be rewritten as the product of the equation (D3) and the probability that travel category $k$ is chosen by those consumers who choose hotel $j$ of travel category $k$. That is

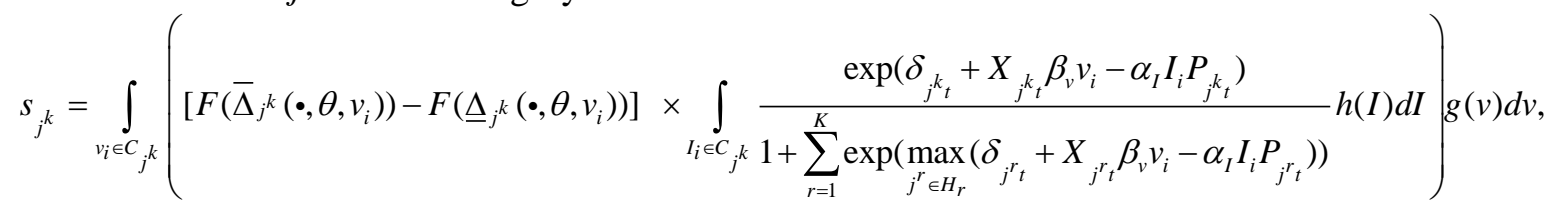

where

$$
h(I)=\frac{f(I)}{F\left(\bar{\Delta}_{j}^{k}\left(\cdot, \theta, v_{i}\right)\right)-F\left(\underline{\Delta}_{j}^{k}\left(\cdot, \theta, v_{i}\right)\right)} .
$$

Again, these integrals are not analytically solvable. Hence, we use a Monte Carlo simulation-based approach to approximate their values based on the distributions $G(v)$ and $H(I)$ :

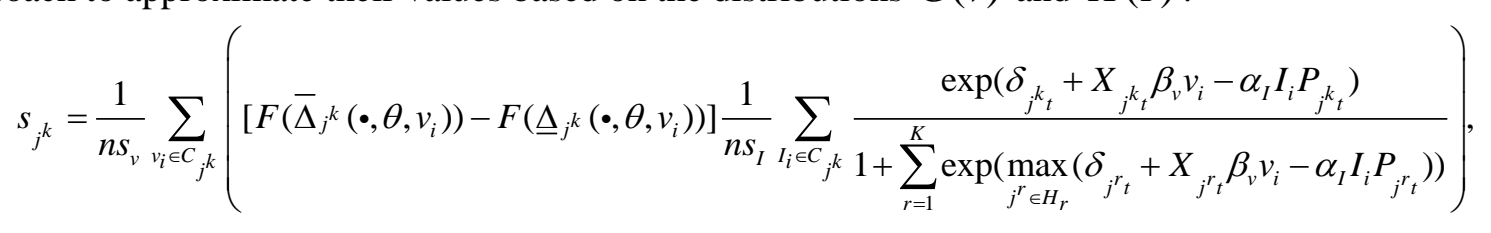

where $n s$ is the number of simulated consumers whose $\alpha \in\left[F\left(\underline{\Delta}_{j} k(\bullet \mid \theta, v)\right), F\left(\bar{\Delta}_{j}^{k}(\bullet \mid \theta, v)\right)\right]$. By restricting the taste shock at a travel category level, this hybrid model combines the choice probabilities of the PCM and the BLP (Song 2010). 


\section{Appendix E1 Estimation Algorithm for the Random Coefficient Demand Model}

The estimation involves two nested loops. In the outer loop, the parameters corresponding to the individual heterogeneity distribution are computed, whereas the inner loop involves computing the unknown parameters embedded in the mean utility. More specifically, we ran the estimation algorithm in the following seven steps.

1. Generate 100 random draws per market for $v_{i}$ and $I_{i}$, from standard normal and income distribution respectively.

2. Initialize starting values $\theta_{0}=\left(\alpha_{I}^{0}, \beta_{v}^{0}\right)$ and $\delta^{0}$.

3. Compute market share within a travel category. This corresponds to the conditional probability calculated by equation (D3), which numerical approximation is shown in equation (D4).

3.1 Sort hotels within each travel category in the order of ascending price;

3.2 For each hotel ${ }_{j}^{k}$ within travel category $k$ in market $t$, calculate the corresponding $\Delta$ value

$$
\Delta=\frac{\left(\delta_{j^{k} t}-\delta_{h^{k}}\right)+\left(X_{j^{k} k_{t}}-X_{h^{k_{t}}}\right) \beta_{v} v_{i}}{\alpha_{I}\left(P_{j^{k}}-P_{h^{k}}\right)},
$$

where $h^{k}$ represents all other hotels in the same market $t$.

3.3 Now, for each travel category $k$ in market $t$, consider all hotels $h^{k}$ ranked before hotel $j^{k}$ (which means those hotels with lower prices than $j^{k}$ ), compute the upper bound

$$
\bar{\Delta}(\bullet \theta \theta, v) \equiv \min _{j^{k}>h^{k}} \frac{\left(\delta_{j^{k} t}-\delta_{h^{k}}\right)+\left(X_{j^{k}}-X_{h^{k_{t}}}\right) \beta_{v} v_{i}}{\alpha_{I}\left(P_{j^{k}}-P_{h^{k}}\right)}
$$

3.4 Similarly, consider all hotels $h^{k}$ ranked after hotel ${ }_{j}^{k}$ (which means those hotels with higher prices than $j^{k}$ ), compute the lower bound

$$
\underline{\Delta}(\bullet \mid \theta, v) \equiv \max _{j^{k}<h^{k}} \frac{\left(\delta_{j^{k}}-\delta_{h^{k_{t}}}\right)+\left(X_{j^{k_{t}}}-X_{h^{k_{t}}}\right) \beta_{v} v_{i}}{\alpha_{I}\left(P_{j^{k}}-P_{h^{k_{t}}}\right)} .
$$

3.5 If the upper bound is strictly higher than the lower bound, then the market share within travel category $k$ is positive

$$
S_{(j \mid c a t e g o r y=k)}=\int\left[F\left(\bar{\Delta}_{j}^{k}(\bullet \mid \theta, v)\right)-F\left(\underline{\Delta}_{j} k(\bullet \mid \theta, v)\right)\right] d G(v) .
$$

Compute by Monte Carlo simulation, with $v_{i}$ from the previous random draws, $n s_{v}=100$,

$$
S_{(j \mid c a t e g o r y=k)} \equiv \frac{1}{n s_{v}} \sum_{i}^{n s}\left[F\left(\bar{\Delta}_{j}^{k}\left(\bullet, \theta, v_{i}\right)\right)-F\left(\underline{\Delta}_{j} k\left(\bullet, \theta, v_{i}\right)\right)\right] .
$$

3.6 Otherwise, the market share within travel category $k$ is zero. 
4. Compute the overall market share function $s_{j^{k}}$ based on equation (D6), which numerical approximation is shown in equation (D7). We achieve this by using the Monte Carlo simulation.

$s_{j^{k}}=\frac{1}{n s_{v}} \sum_{v_{i} \in C_{j} k}\left(\left[F\left(\bar{\Delta}_{j^{k}}\left(\cdot, \theta, v_{i}\right)\right)-F\left(\underline{\Delta}^{k}\left(\cdot, \theta, v_{i}\right)\right)\right] \frac{1}{n s_{I}} \sum_{I_{i} \in C_{j} k} \frac{\exp \left(\delta_{j^{k}}+X_{j^{k}} \beta_{v} v_{i}-\alpha_{I} I_{i} P_{j^{k}}\right)}{1+\sum_{r=1}^{K} \exp \left(\max _{j^{r} \in H_{r}}\left(\delta_{j^{r} t}+X_{j^{r} t} \beta_{v} v_{i}-\alpha_{I} I_{i} P_{j^{r}}\right)\right)}\right)$,

where $v_{i}$ and $I_{i}$ are from the previous random draws, with $n s_{v}=n s_{I}=100$.

5. The inner loop computation takes place. Keeping the nonlinear parameters fixed at the initial guesses, iterate over the values of the mean utility $\delta$ to minimize the distance between the predicted market share and the observed market share. This requires to solve the system of nonlinear equations, $s(\delta)$, where $\delta$ is a $n$-dimension vector of unknown variables $\left(n=\sum_{k=1}^{K} J^{k}\right.$ ). This can be done by using Newton-Raphson Method.

5.1 Compute the Jacobian matrix $J(\delta)$ for $s(\delta)$ :

$$
J(\delta)=\left[\begin{array}{ccc}
\frac{\partial s_{1}}{\partial \delta_{1}} & \cdots & \frac{\partial s_{1}}{\partial \delta_{n}} \\
\cdots & \cdots & \cdots \\
\frac{\partial s_{n}}{\partial \delta_{1}} & \cdots & \frac{\partial s_{n}}{\partial \delta_{n}}
\end{array}\right] .
$$

5.2 Given a starting value of $\delta^{0}$, solve the nonlinear system by iteration:

$$
J\left(\delta^{m}\right)\left(\delta^{m+1}-\delta^{m}\right)=-s\left(\delta^{m}\right), \quad m=m+1, \text { until }\left\|\delta^{m+1}-\delta^{m}\right\|<\varepsilon .
$$

5.3 Given the solved $\delta$, extract the unobserved characteristic $\xi$

$$
\xi=\delta-X \bar{\beta}+\bar{\alpha} P \text {. }
$$

6. Form a GMM objective function by interacting the unobserved characteristic, $\xi$, with the instrumental variable $I V$ :

$$
G M M o b j=E\left[\xi^{\prime} \cdot I V\right]
$$

7. The outer loop computation takes place. Given $\delta$ computed in step 5, minimize the GMM objective function with respect to $\alpha_{I}$ and $\beta_{v}$, to find the new $\theta_{1}=\left(\alpha_{I}^{1}, \beta_{v}^{1}\right)$. Assign $\theta_{1}=\left(\alpha_{I}^{1}, \beta_{v}^{1}\right)$ and $\delta$ as the new starting value and iterate from step 3 , until the algorithm finds the optimal combination of $\alpha_{I}, \beta_{v}$ and $\delta$, which minimizes the GMM objective function. 


\section{Appendix E2 Model Identification}

One important issue in the estimation procedure that was pointed out by Berry (1994), and Berry and Pakes (2007) was to prove the "existence and uniqueness of $\xi$." In other words, it is critical to illustrate that, for each pair of $\left(\alpha_{I}, \beta_{v}\right)$ and distribution of consumer characteristics, there exists a unique value of $\xi$ which makes the model predicted market shares equal to the observed market shares.

As defined in Berry and Pakes (2007), we let $r(s, \xi)$ denote the "element-by-element" inverse function for a product, where $s$ represents the model predicted market share. The value of $\xi$ exists and is unique, if there is a unique solution to the fixed point:

$$
\xi=r(s, \xi) \text {. }
$$

For this unique fixed point to exist, the model predicted market share function must have the following three properties: (i) monotonicity $-s_{j}$ is weakly increasing and continuous in $\xi_{j}$ and weakly decreasing in $\xi_{-j}$, where $\xi_{-j}$ is the unobserved characteristics for the rival-products, (ii) linearity of utility in $\xi$ - if $\xi$ for every good is increasing by an equal amount, then no market share changes, and (iii) substitutes with some other good - every product must be a strict substitute with some other good.

These three properties hold for both the BLP (Berry 1994) and PCM (Berry and Pakes 2007) types of models. Since the market share function in our model is constructed in a "tight-coupling" fashion, based on the combination of the two models (i.e., $s_{t w o-s t e p}(\xi) \sim S_{B L P}(\xi) s_{P C M}(\xi)$ ), one can illustrate that the combined market share function also preserves all of the three properties from the two individual components. Therefore, there exists a unique value of $\xi$ which makes the model predicted market shares just equal to the observed market shares, hence, supporting the "existence and uniqueness of $\xi$." 30

\footnotetext{
${ }^{30}$ Further information on the proof of existence and uniqueness of the mean product quality (delta parameter that matches the model predicted market shares with observed market share) is available in Song (2009). This is in addition to Berry et al. (2004) who provide support for their arguments regarding the asymptotic properties for the multi-dimensional pure characteristics model with Monte Carlo simulations.
} 


\section{Appendix F More Details on the BLP Model}

For model comparison purpose, we introduced the classical BLP model as one of our baseline models. The basic assumptions for the BLP model are very similar to the ones in the two-step model. The only key difference is that in the BLP model, instead of a travel category-level taste shock with a superscript $k, \varepsilon_{i t}^{j}$ is defined as a hotel-level taste shock with a superscript $j$. Thus, the utility for each hotel is modeled correspondingly as below.

$$
u_{i j t}=X_{j t} \beta_{i}-\alpha_{i} P_{j t}+\xi_{j t}+\varepsilon_{i t}^{j},
$$

Where: $i$ represents a consumer, $j$ represents hotel, and $t$ represents a hotel market on a given date, which is defined as a "city-night" combination same as in the two-step model. $\xi$ represents the unobserved hotel characteristics and $\varepsilon_{i t}^{j}$ represents the hotel-level taste shock. $\beta_{i}$ and $\alpha_{i}$ are random coefficients, which is assumed to follow normal distribution with means $(\bar{\beta}, \bar{\alpha})$ and the standard deviations $\left(\sigma_{\beta i}, \sigma_{\alpha i}\right)$. Similarly, we assume that $\sigma_{\alpha i} \sim \alpha_{I} I_{i}$, where $I_{i}$ represents consumer $i$ 's income; $\sigma_{\beta i} \sim \beta_{v} v_{i}$, where $v_{i} \sim N(0,1)$ represents the unobserved consumer characteristic. Thus, the BLP model can be written in the following form:

$$
u_{i j t}=\delta_{j t}+X_{j t} \beta_{v} v_{i}-\alpha_{I} I_{i} P_{j t}+\varepsilon_{i t}^{j},
$$

Where: $\delta_{j t}=X_{j t} \bar{\beta}-\bar{\alpha} P_{j t}+\xi_{j t}$, represents the mean utility of hotel $j$ in market $t$. Similar as in the basic two-step model, $\beta_{v}$ and $\alpha_{I}$ are the set of parameters to be estimated. According to BLP (1995), the market share can be derived as

$$
s_{j}=\iint \frac{\exp \left(\delta_{j t}+X_{j t} \beta_{v} v_{i}-\alpha_{I} I_{i} P_{j t}\right)}{1+\sum_{r=1}^{J} \exp \left(\delta_{r t}+X_{r t} \beta_{v} v_{i}-\alpha_{I} I_{i} P_{r t}\right)} f(I) g(v) d I d v .
$$

As an extension, besides the income and the unobserved consumer characteristic, to capture more interaction effects with consumer demographics, we further incorporate consumer's travel purpose by assuming the standard deviations to be functions of consumer's travel purpose: $\sigma_{\alpha i} \sim \alpha_{I} I_{i}+\alpha_{T} T_{i}$, and $\sigma_{\beta i} \sim \beta_{v} v_{i}+\beta_{T} T_{i}$, where $T_{i}$ is an indicator vector denoting consumer $i$ 's travel purpose:

$$
T_{i}{ }^{\prime}=\left[\text { Family }_{i} \text { Business }_{i} \text { Romance }_{i} \text { Tourist }_{i} \text { Kids }_{i} \text { Seniors }_{i} \text { Pets }_{i} \text { Disability }_{i}\right] .
$$

For example, if consumer $i$ is on a business trip, then the corresponding travel purpose vector is

$$
T_{i}{ }^{\prime}=\left[\begin{array}{llllllll}
0 & 1 & 0 & 0 & 0 & 0 & 0 & 0
\end{array}\right] \text {. }
$$

Thus, the overall utility function can be thereby written as

$$
u_{i j t}=\delta_{j t}+X_{j t} \beta_{v} v_{i}+X_{j t} \beta_{T} T_{i}-\alpha_{I} I_{i} P_{j t}-\alpha_{T} T_{i} P_{j t}+\varepsilon_{i t}^{j} .
$$

In this case, our goal is to estimate $\beta_{v}, \beta_{T}, \alpha_{I}, \alpha_{T}$. Notice that $\beta_{T}$ is a weight matrix representing the interaction effects between consumer travel purpose and hotel characteristics, while $\alpha_{T}$ is a vector representing the interaction effect between consumer travel purpose and hotel price. 


\section{Appendix G}

\section{Comparison of Mechanical Turk Users with overall US Internet Population}

\begin{tabular}{|c|c|c|c|}
\hline & June 2008 & October 2008 & December 2008 \\
\hline & $\begin{array}{l}\text { US Internet Users } \\
\text { comscore Data }\end{array}$ & Mechanical Turk Users & Mechanical Turk Users \\
\hline Total Audience & 100 & 100 & 100 \\
\hline \multicolumn{4}{|l|}{ Persons - Age } \\
\hline Persons: $15+$ & 85.9 & 100 & 100 \\
\hline Persons: $18+$ & 80.1 & 99.6 & 99.5 \\
\hline Persons: 21+ & 74.3 & 92.9 & 91.1 \\
\hline Persons: $35+$ & 52.4 & 39.3 & 37.1 \\
\hline Persons: 50+ & 24.3 & 11.2 & 10.7 \\
\hline Persons: 55+ & 16.2 & 5.2 & 5.4 \\
\hline Persons: 2-11 & 9.5 & 0 & 0 \\
\hline Persons: 2-17 & 19.9 & 0.2 & 0.4 \\
\hline Persons: 6-11 & 7.4 & 0 & 0 \\
\hline Persons: 6-14 & 12 & 0 & 0 \\
\hline Persons: 9-14 & 8.9 & 0 & 0 \\
\hline Persons: $12-17$ & 10.4 & 0.2 & 0.4 \\
\hline Persons: $12-24$ & 22.9 & 19 & 21.5 \\
\hline Persons: $12-34$ & 38 & 57.8 & 60 \\
\hline Persons: $12-49$ & 66.2 & 87.4 & 88.2 \\
\hline Persons: $18-24$ & 12.5 & 18.7 & 21.1 \\
\hline Persons: $18-34$ & 27.6 & 57.5 & 59.7 \\
\hline Persons: $18-49$ & 55.8 & 87.2 & 87.8 \\
\hline Persons: $21-34$ & 21.9 & 53.3 & 53.9 \\
\hline Persons: $21-49$ & 50 & 82.9 & 82 \\
\hline Persons: $25-34$ & 15.1 & 38.8 & 38.6 \\
\hline Persons: $25-49$ & 43.2 & 68.4 & 66.7 \\
\hline Persons: $25-54$ & 51.3 & 75.2 & 72.3 \\
\hline Persons: $35-44$ & 18.7 & 22.4 & 21.5 \\
\hline Persons: $35-49$ & 28.2 & 29.7 & 28.1 \\
\hline Persons: $35-54$ & 36.2 & 36.4 & 33.7 \\
\hline Persons: $35-64$ & 46.8 & 41.4 & 38.8 \\
\hline Persons: $45-54$ & 17.6 & 14 & 12.2 \\
\hline Persons: 45-64 & 28.1 & 19 & 17.4 \\
\hline Persons: 55-64 & 10.5 & 5 & 5.2 \\
\hline Persons: 65+ & 5.7 & 0.7 & 1.1 \\
\hline \multicolumn{4}{|l|}{ Males - Age } \\
\hline All Males & 49.5 & 28 & 36.6 \\
\hline Male: $15+$ & 42.1 & 28 & 36.6 \\
\hline Male: $18+$ & 39.1 & 27.8 & 36.3 \\
\hline Male: $21+$ & 36.1 & 24.7 & 32.4 \\
\hline Male: $35+$ & 25.7 & 9.5 & 11.3 \\
\hline Male: $50+$ & 12 & 2.8 & 2.6 \\
\hline Male: 55+ & 8.1 & 1.4 & 1.1 \\
\hline Male: $2-11$ & 4.9 & 0 & 0 \\
\hline
\end{tabular}




\begin{tabular}{|c|c|c|c|}
\hline Male: $2-17$ & 10.4 & 0.1 & 0.2 \\
\hline Male: 6-11 & 3.9 & 0 & 0 \\
\hline Male: 6-14 & 6.3 & 0 & 0 \\
\hline Male: $9-14$ & 4.5 & 0 & 0 \\
\hline Male: $12-17$ & 5.5 & 0.1 & 0.2 \\
\hline Male: $12-24$ & 11.6 & 7.5 & 9.1 \\
\hline Male: $12-34$ & 18.9 & 17.3 & 24.2 \\
\hline Male: $12-49$ & 32.5 & 25 & 33.9 \\
\hline Male: $18-24$ & 6.1 & 7.4 & 8.9 \\
\hline Male: $18-34$ & 13.4 & 17.2 & 23.9 \\
\hline Male: $18-49$ & 27.1 & 24.9 & 33.7 \\
\hline Male: $21-34$ & 10.4 & 15.2 & 21.1 \\
\hline Male: $21-49$ & 24.1 & 22.9 & 30.8 \\
\hline Males: $25-34$ & 7.3 & 9.8 & 15 \\
\hline Male: $25-49$ & 20.9 & 17.6 & 24.8 \\
\hline Male: $25-54$ & 24.8 & 19 & 26.3 \\
\hline Males: $35-44$ & 9.1 & 6 & 8 \\
\hline Male: $35-49$ & 13.7 & 7.7 & 9.7 \\
\hline Male: $35-54$ & 17.5 & 9.1 & 11.2 \\
\hline Male: $35-64$ & 22.6 & 10.6 & 12.3 \\
\hline Male: $45-54$ & 8.4 & 3.1 & 3.2 \\
\hline Male: $45-64$ & 13.5 & 4.5 & 4.3 \\
\hline Males: 55-64 & 5.1 & 1.4 & 1.1 \\
\hline Males: $65+$ & 3 & 0 & 0.1 \\
\hline \multicolumn{4}{|l|}{ Females - Age } \\
\hline All Females & 50.5 & 72 & 63.4 \\
\hline Female: $15+$ & 43.8 & 72 & 63.4 \\
\hline Female: $18+$ & 41 & 71.9 & 63.3 \\
\hline Female: $21+$ & 38.2 & 68.2 & 58.7 \\
\hline Female: $35+$ & 26.8 & 29.8 & 25.8 \\
\hline Female: $50+$ & 12.3 & 8.3 & 8.1 \\
\hline Female: $55+$ & 8.1 & 3.8 & 4.3 \\
\hline Female: $2-11$ & 4.6 & 0 & 0 \\
\hline Female: $2-17$ & 9.5 & 0.1 & 0.1 \\
\hline Female: $6-11$ & 3.6 & 0 & 0 \\
\hline Female: $6-14$ & 5.7 & 0 & 0 \\
\hline Female: $9-14$ & 4.5 & 0 & 0 \\
\hline Female: $12-17$ & 4.9 & 0.1 & 0.1 \\
\hline Female: $12-24$ & 11.3 & 11.5 & 12.3 \\
\hline Female: $12-34$ & 19.1 & 40.5 & 35.9 \\
\hline Female: $12-49$ & 33.6 & 62.4 & 54.3 \\
\hline Female: $18-24$ & 6.4 & 11.5 & 12.2 \\
\hline Female: $18-34$ & 14.2 & 40.5 & 35.8 \\
\hline Female: $18-49$ & 28.7 & 62.4 & 54.1 \\
\hline Female: $21-34$ & 11.5 & 38.1 & 32.8 \\
\hline Female: $21-49$ & 25.9 & 60 & 51.2 \\
\hline Females: $25-34$ & 7.8 & 28.9 & 23.6 \\
\hline Female: $25-49$ & 22.3 & 50.9 & 41.9 \\
\hline Female: $25-54$ & 26.5 & 56.2 & 46 \\
\hline Females: $35-44$ & 9.5 & 16.4 & 13.4 \\
\hline
\end{tabular}




\begin{tabular}{|c|c|c|c|}
\hline Female: $35-49$ & 14.5 & 21.9 & 18.4 \\
\hline Female: $35-54$ & 18.7 & 27.3 & 22.4 \\
\hline Female: $35-64$ & 24.1 & 30.8 & 26.5 \\
\hline Female: $45-54$ & 9.2 & 10.9 & 9 \\
\hline Female: $45-64$ & 14.6 & 14.5 & 13.1 \\
\hline Females: 55-64 & 5.4 & 3.6 & 4.1 \\
\hline Females: $65+$ & 2.6 & 0.7 & 1 \\
\hline \multicolumn{4}{|l|}{ HH Income (US) } \\
\hline HHI USD: Less than 15,000 & 6 & 11.4 & 12.9 \\
\hline HHI US: Under $\$ 25 \mathrm{~K}$ & 9.3 & 22.8 & 23.1 \\
\hline HHI US: Under $\$ 60 \mathrm{~K}$ & 44.5 & 64.8 & 60.5 \\
\hline HHI US: $\$ 60 \mathrm{~K}+$ & 55.5 & 34.8 & 39.1 \\
\hline HHI US: \$75K+ & 43 & 22.7 & 27.5 \\
\hline HHI USD: $15,000-24,999$ & 3.4 & 11.4 & 10.1 \\
\hline HHI USD: 25,000 - 39,999 & 9.9 & 21.8 & 18.9 \\
\hline HHI USD: 40,000 - 59,999 & 25.3 & 20.2 & 18.6 \\
\hline HHI USD: $60,000-74,999$ & 12.6 & 12.1 & 11.6 \\
\hline HHI USD: 75,000 - 99,999 & 17.7 & 10.2 & 11.5 \\
\hline HHI USD: 100,000 or more & 25.3 & 12.5 & 16 \\
\hline \multicolumn{4}{|l|}{$\underline{\text { Region (US) }}$} \\
\hline $\begin{array}{l}\text { Region US:West North } \\
\text { Central }\end{array}$ & 7.6 & 5.8 & 7.5 \\
\hline Region US:Mountain & 6.9 & 6.4 & 7.4 \\
\hline Region US:Pacific & 15.4 & 13.3 & 15.7 \\
\hline Region US:New England & 5.5 & 6.4 & 4.7 \\
\hline Region US:Mid Atlantic & 14.2 & 13.9 & 15.8 \\
\hline Region US:South Atlantic & 18.7 & 19.2 & 19.9 \\
\hline $\begin{array}{l}\text { Region US:East South } \\
\text { Central }\end{array}$ & 5.1 & 8.3 & 5.2 \\
\hline $\begin{array}{l}\text { Region US:West South } \\
\text { Central }\end{array}$ & 10.5 & 10.7 & 9 \\
\hline $\begin{array}{l}\text { Region US:East North } \\
\text { Central }\end{array}$ & 16.1 & 15.7 & 14.8 \\
\hline \multicolumn{4}{|l|}{ Children } \\
\hline Children:No & 39.3 & 52.7 & 57.6 \\
\hline Children:Yes & 60.7 & 47.3 & 42.3 \\
\hline \multicolumn{4}{|l|}{ HH Size } \\
\hline HH Size: 1 & 4.4 & 17.7 & 17.3 \\
\hline HH Size: 2 & 24.2 & 28.9 & 30.6 \\
\hline HH Size: 3 & 21.4 & 19.7 & 19.2 \\
\hline HH Size: 4 & 25.3 & 20.5 & 21.9 \\
\hline HH Size: $5+$ & 24.8 & 12.9 & 10.7 \\
\hline HH Size: $1-2$ & 28.5 & 46.6 & 47.8 \\
\hline HH Size: $3+$ & 71.5 & 33.5 & 32.7 \\
\hline \multicolumn{4}{|l|}{ Race } \\
\hline Race:White & 87.3 & 82.7 & 82 \\
\hline Race:Black & 8 & 6.5 & 5.3 \\
\hline Race:Asian & 1.6 & 5.7 & 6.8 \\
\hline Race:Other & 3.1 & 4.9 & 5.8 \\
\hline
\end{tabular}

